\title{
Fine particulate matter in indoor cultural heritage: a literature review
}

\author{
Josep Grau-Bové* and Matija Strlič
}

\begin{abstract}
Fine particulate matter is, on account of its aerodynamic properties and typical composition (especially diesel particulate matter and carbonaceous particles) the particulate pollutant potentially most harmful to cultural heritage, representing an aesthetic issue and an agent of chemical degradation simultaneously. This paper reviews the current knowledge of the life-cycle of fine particulates, focussing on diesel particulate matter from emission to deposition, including its aesthetic and chemical consequences, and draws attention to some imbalances in the current state of research. The currently available measurements are biased towards coarse dust, and information on the consequences of particle deposition is largely restricted to the outdoor environment. More evidence on the chemical effects of the most common types of fine particulate matter in typical indoor materials is needed to enable risk assessment for indoor collections.
\end{abstract}

Keywords: Fine particulate matter, Diesel particulate matter, Soiling, Deposition, Resuspension, Indoor air quality, Indoor heritage

\section{Introduction}

Most museums, galleries, libraries and archives, as well as many historical palaces and houses, are located in urban centres, surrounded by a complex and changeable urban atmosphere. While the last twenty years have seen a great reduction in the emissions of the pollutants that have been typically considered more harmful for vulnerable heritage materials, scientific interest is shifting towards other pollutants and particulate matter (PM) has been a subject of great interest.

However, PM can be an elusive subject of study. Different sizes display different properties, typical sources and even different behaviours. Studies of PM in indoor heritage environments have generally focused on dust, which is one of the characteristic sizes -the largest- of PM. This bias towards coarse particles is evident if we look at the minimum diameter of the particles collected in different monitoring campaigns in the field of heritage science. A survey of 25 scientific papers [1-25], most of them reviewed here, with the keywords "heritage" and "particulate matter" reveal that $32 \%$ of them analyse only particles

${ }^{*}$ Correspondence: josep.grau-bove.11@ucl.ac.uk

Centre for Sustainable Heritage, University College London, Central House, 14 Upper Woburn Place, WC1H ONN, London up to $10 \mu \mathrm{m}$ and $16 \%$ include particles up to $2.5 \mu \mathrm{m}$, i.e. more than half of the studies did not look into submicron particles. If a study did take into account particles $\sim 0.5$ $1 \mu \mathrm{m}$, it is generally the lowest size mode considered (36\% of cases) and no particles are studied under this value. Finally, in $92 \%$ of the cases, particles are studied in only two or one size modes (usually 2.5 and $10 \mu \mathrm{m}$ ). However, two size fractions are not enough to reflect the actual size distribution, which is only analysed in a minority (8\%) of the studies.

Obtaining size distributions and specifically quantifying the amount of submicron particles is common practice in aerosol monitoring outside the heritage field. All these sizes, and not only large particles, have a certain role in indoor heritage environments. In fact, coarse particles exhibit characteristics of great interest to conservators: they are significant carriers of mass to surfaces, and, being bigger, are more likely to alter the visual appearance of objects. But their number concentrations are orders of magnitude smaller than the concentrations of fine particles, especially in urban environments. Additionally, the composition of coarse and ultrafine particles is also different, and while small particles might carry less mass, they may carry components of different reactivity. 
This review deals with fine particles, i.e. all particles smaller than $1 \mu \mathrm{m}$, without excluding particles smaller than $0.1 \mu \mathrm{m}$, commonly referred to as ultrafine (UFP). This size range is clearly separated from coarse dust, and it includes pollutants of particular interest to conservation of cultural heritage. Special attention will be given to particles derived from combustion present in urban environments, particularly Diesel Particulate Matter (DPM).

The review serves a double purpose. First of all, it attempts to identify if fine and ultrafine particles can be regarded as a relevant risk to cultural heritage indoors. It also identifies multiple areas that require further research. Secondly, it aims to provide a guide to heritage managers and curators interested in the properties of this particular pollutant. While aerosols indoors have been studied in detail, no account exists of the distinct behaviour of fine particles. Since not many investigations deal directly with fine and ultrafine particles in heritage environments, this review will make use of work produced in other fields -aerosol science, environmental science, computational modelling- which can be applied to heritage at least partly.

\section{Sources, trends, and projections}

The term PM identifies all the particles that can be found in the atmosphere, in other words, those that can be suspended in air and transported by it before they deposit. This includes particles composed only of several molecules, with diameters around $0.01 \mu \mathrm{m}$, up to coarse dust with diameters around $100 \mu \mathrm{m}$. Samples of atmospheric PM usually display a very characteristic size distribution, clearly separated in three different size modes (Figure 1) [26]. These modes are referred to as the nucleation, ultrafine, or Aitken mode $(<100 \mathrm{~nm})$, coagulation or accumulation mode (100 - $1000 \mathrm{~nm})$ and coarse mode $(>1 \mu \mathrm{m})$. An alternative and common nomenclature is using $P M_{x}$ for all the particles smaller than $x$ in $\mu m$, the usual values being 10, $2.5 \mu \mathrm{m}$ or, less commonly, 5 and $1 \mu \mathrm{m}$. Although the use of this notation is widely spread, it makes an artificial division between the actual size modes. E.g., $P M_{2.5}$ is in the middle of the coarse mode but is generally taken as a good indication of the amount of anthropogenic particulate pollutants in urban environments. This nomenclature is useful from the health perspective as it approximately denotes the fractions which can penetrate to different depths of the human respiratory system. It is not, as we shall see, particularly suited for heritage purposes. However, its status of a standard makes its use unavoidable.

Given such a broad definition, it is natural that there are a variety of origins, sources and compositions of PM. Nonetheless, there are a limited number of relevant sources. The majority are related to energy production, and natural sources (such as sea-spray) are often negligible in comparison with the anthropogenic ones. Among them, the combustion of fossil fuels, especially in road transportation, has a prominent role.

In the UK, road transport is responsible for more than half of the particles of the smaller size ranges and around $20 \%$ of the larger [27]. This relative contribution is even greater in urban areas. At Marylebone Road, arguably one of the most polluted streets in London, traffic-generated particles make up to $27 \%$ of the $P M_{10}$ mass concentration and $42 \%$ of the $P M_{2.5}$ [28]. Most road transport particles are due to diesel vehicles (e.g. 72\% of USA road transport PM) [29]. Even though this picture varies greatly between regions, similar particle source apportionments have been reported by different studies carried out elsewhere [30,31].

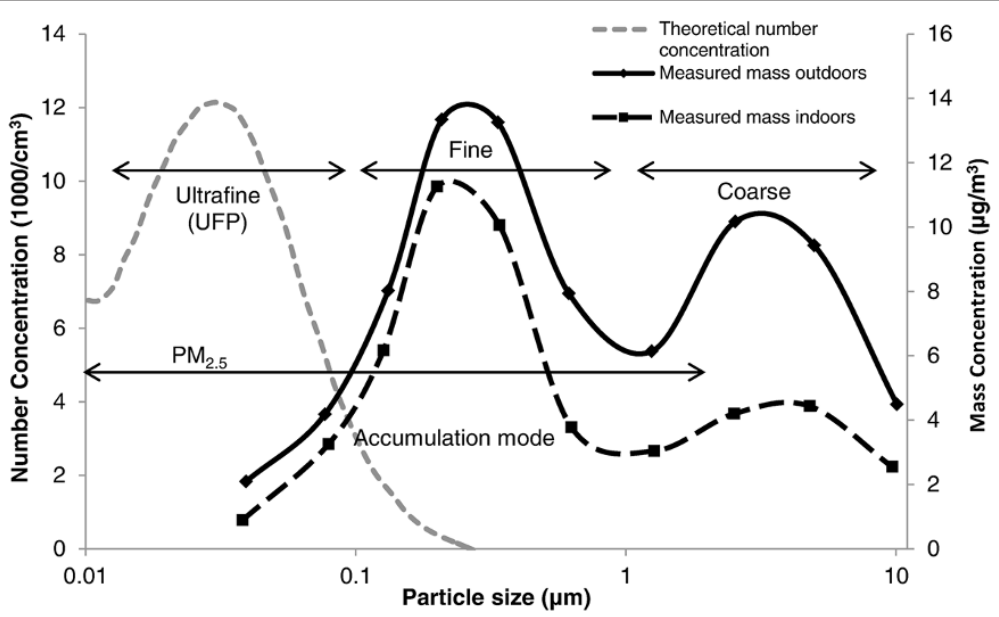

Figure 1 Typical size distribution. An example of distribution of atmospheric particles showing the relevant and typical properties of DPM. Mass concentrations adapted from measurements taken in the National Library in Prague [24] and completed with theoretical number concentration of ultrafine particles according to [26]. 
Emissions of all types of PM are predicted to decrease in the decades to come, including emissions of the smallest particles [32] due to the implementation of mitigation strategies such as diesel soot filters and the substitution of fossil fuels with alternative energy sources. Analysis of global emission trends under different scenarios reveal that emissions of traffic-generated PM will reduce in all the continents except in Africa, where they are predicted to increase 1.3 - 3.1\% per year, depending on the scenario, due to economic development and ageing car fleet. Global emissions from vehicles will reduce $1.3-2 \%$ on average per year in the following 40 years [33]. China will achieve a reduction in emissions of black carbon of 9\% by 2020 [34].

The PM concentration limit suggested by the World Health Organisation (WHO) [35] and the European Commission [36] for $P M_{2.5}$ is $25 \mu \mathrm{g} / \mathrm{m}^{3}$, and the US Environmental Protection Agency has suggested a value of 13 $\mu g / m^{3}$. Even though these limits are exceeded in some regions, it is likely that they will be satisfied in the near future. However, WHO states as no threshold for PM has been identified below which no damage to health is observed, the recommended value should represent an acceptable and achievable objective to minimize health effects in the context of local constraints, capabilities and public health priorities [35]. The same logic may be applicable to heritage materials. It can be concluded that, even though emissions are gradually decreasing, trafficgenerated pollutants will remain an important part of urban atmospheres for decades, especially in developing economies.

\section{Particles derived from combustion}

The laser-cleaning literature abounds with uses of the word "soot", referring to dark deposits on indoor and outdoor materials. However, no standard description or characterisation of soot exists. The concept of "black carbon", extensively used in aerosol and environmental science, suffers from a similar imprecision, sometimes used interchangeably with soot [37].

What is clear is that fine particles $\left(P M_{1}\right)$ mostly originate from combustion processes. Morphology and composition of these particles varies with the source to some degree: burning of candles, coal, tobacco or diesel fuel. These particles also have common features: a high content of inorganic carbon that will display high light absorbance, combined or coated with traces of other elements, and an aggregate-like shape.

\section{Diesel particulates}

A typical diesel particulate is shown in its graphic representation in Figure 2a and a TEM micrograph in Figure $2 b$ [38]. Diesel particulates in the accumulation mode have a distinct morphology consisting of a self-similar agglomeration of primary particles, which has led some researchers to use fractality as a characterisation factor [39]. These primary particles are mainly composed of elemental carbon with metallic traces, and are coated with a layer of organic carbon and sulfate. This composition is subject to some variability as it depends on the engine type, the engine load and the fuel used. Total carbon usually accounts for $75-90 \%$ of the overall mass [40], and the metal traces can include, in the order of relative abundance: $\mathrm{Ca}, \mathrm{Fe}, \mathrm{Mg}, \mathrm{Zn}, \mathrm{Cr}, \mathrm{Ni}, \mathrm{Ba}, \mathrm{Pb}[41,42]$. Elemental carbon (EC) is a characteristic component of DPM, which is typically the source of $90 \%$ of the $\mathrm{EC}$ in urban environments [43]. Organic Carbon (OC) may be emitted directly into the atmosphere or can be formed in gas-toparticle atmospheric processes (secondary aerosol). EC, on the other hand, emerges primarily from the combustion of carbonaceous matter, and its presence is generally regarded as a good indicator of the fossil fuel combustion origin of PM, especially in urban areas. Recently,
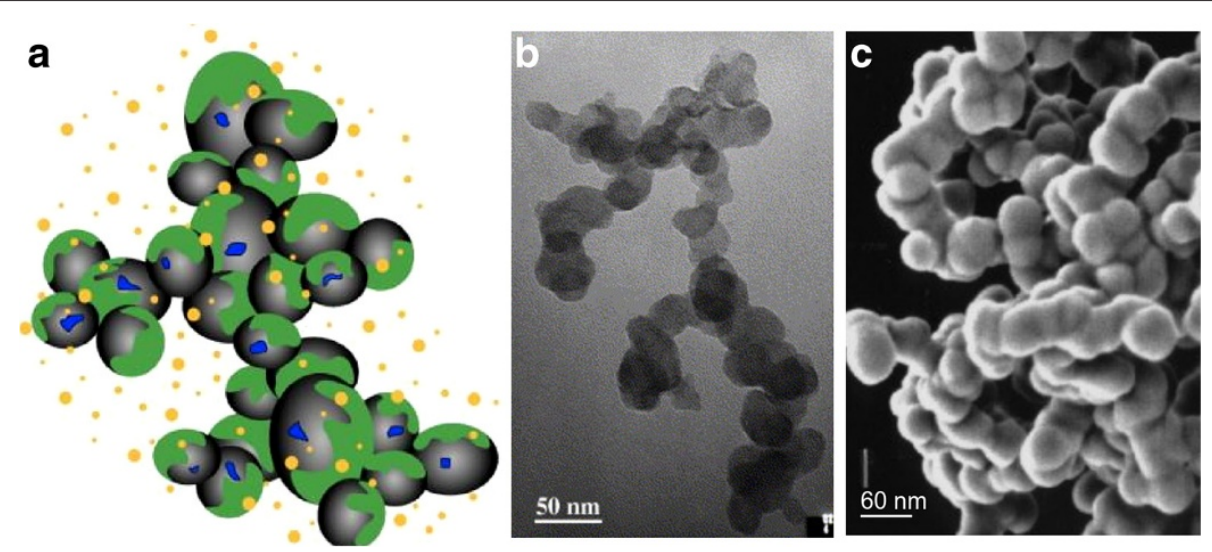

Figure 2 Combustion-derived particles. a) Graphic representation of a typical diesel particle containing all its components: EC substrate, OC coating, metal traces and nucleation particles, taken from [41]. b) TEM image of a diesel exhaust particle with a magnification of 230000x, taken from [38]. c) A candle soot particulate displaying a morphology similar to that of DPM [46]. 
however, it has been claimed that atmospheric EC can originate from sources other than diesel exhausts [31,44], which makes source apportionment difficult. Polycyclic aromatic hydrocarbons (PAHs) and $n$-alkanes have also been suggested as possible tracers for different particulate pollutants generated by road traffic [45].

\section{Other combustion particulates}

Even though this review focuses on particles of outdoor origin, mention should be made of other specific sources of fine and ultrafine particles which may be of interest. Candle-burning soot, for example, is commonly associated with indoor deposits in temples and churches. It has been found that the amount and composition of particles emitted from candles depend on the burning mode. If the flame is in steady state, it emits a relatively high number of ultrafine particles dominated by either phosphates or alkali nitrates originated from additives. Sooting burn, in addition, emits larger particles mainly consisting of agglomerated elemental carbon, with a morphology which is similar to DPM [47] (Figure 2c). Particles with the same morphology [46] and similar composition can be emitted during cooking [48], an activity not unusual in large heritage sites and museums. A "black deposit" or "soot deposit", must, therefore, be assessed with care in order to identify the most likely origin of the particles.

\section{Concentration trends indoors}

The indoor PM concentration is generally a reflection of the outdoor concentration. Certain indoor activities represent exceptions to this rule. It has long been established that different activities, such as cooking, housework, or simply any physical activity, result in concentration peaks over the baseline set by the outdoor concentration [49].
The frequency of these activities in heritage environments, and the efficiency of air cleaning systems define the daily PM pattern.

Fine PM such as DPM originate from outdoor sources, and the events that can cause a drop or a sudden increase in its concentration are rare. Figure 3 shows the variation of fine particle $(\mathrm{d}<1 \mu \mathrm{m})$ concentration in a roadside house. It can be clearly appreciated that the indoor concentration is a consequence of the outdoor concentration, except when particles are emitted during cooking activities.

In heritage environments, indoor events that lead to emission of fine particles are uncommon. Actions such as cleaning, or physical activity cause variations in the concentration of the larger particles, but generally leave the smaller size modes unaltered. Figure 4 shows the variation of airborne particle concentration in the Correr Museum, Italy [17]. It can be appreciated that the peaks of 10, 5, 2 , and $1 \mu \mathrm{m}$ particles, which correspond with the opening hours of the museum, as well as their high variability, are not reflected in the concentration pattern of the finer particles, which varies smoothly. Very similar temporal evolutions have been reported in the Anatomy Theatre of Padua [7] and in the Chiericati Municipal Museum of Vicenza, Italy [50]. As a general rule, while physical movement increases the number of coarse particles, actions involving heating tend to increase the concentration of the smallest particles. Air heaters, electrical radiators and stoves have been found to increase concentrations of particles between $0.02-0.1 \mu \mathrm{m}$ up to 100,000 200,000 particles $/ \mathrm{cm}^{3}$, while leaving larger particles unaltered [51].

The mass and number concentrations seen in Figures 3 and 4 are representative of the typical concentrations in indoor environments. The average concentration of $P M_{1}$

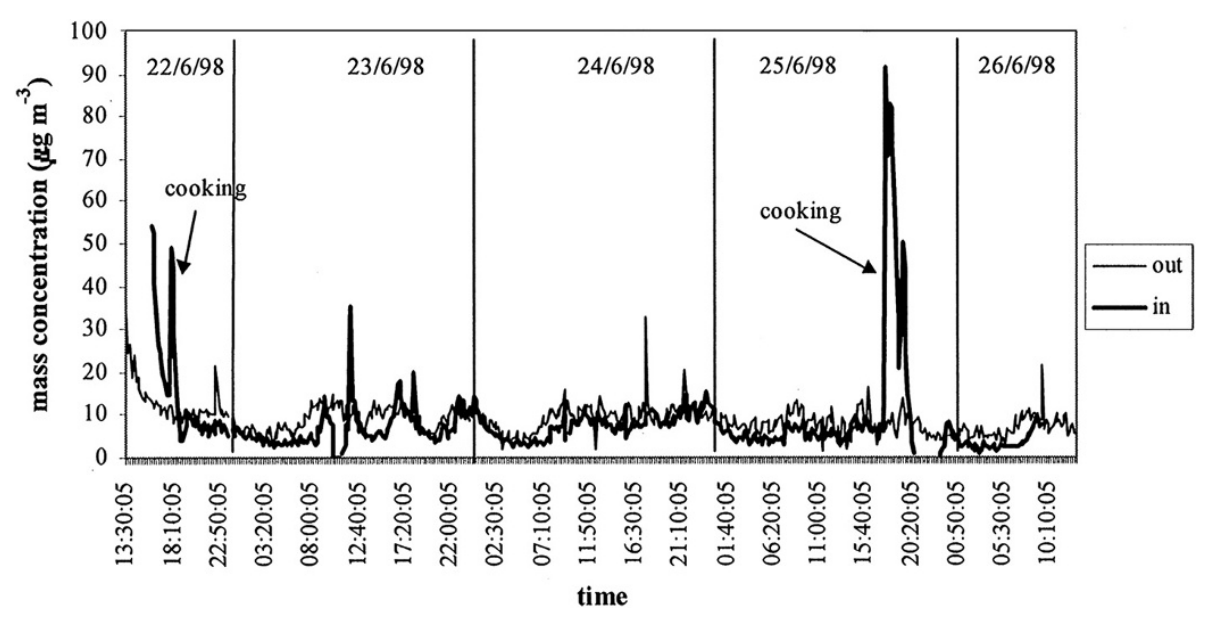

Figure 3 Outdoor and indoor variations of PM conentration. Indoor and outdoor variations of fine particle concentration $(\mathrm{d}<1 \mu \mathrm{m})$ in a roadside house in Birmingham (Taken from [49]). 


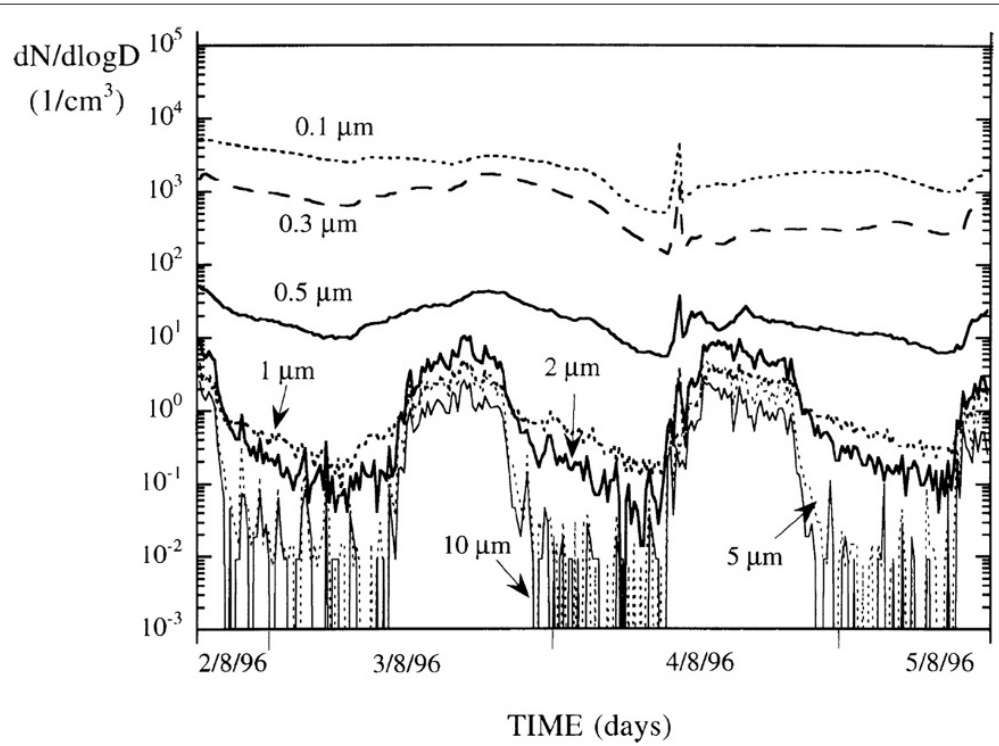

Figure 4 PM in the Correr Museum. Variation of particulate matter concentrations in the Correr Museum, Venice, Italy, taken from [17].

inside the Alhambra, Granada, Spain, was $17 \mu g / m^{3}$ in summer and $8 \mu \mathrm{g} / \mathrm{m}^{3}$ in winter [2], and its most abundant component was black carbon. Traffic was found to be the major source of fine particles. Between 10 and 20 $\mu \mathrm{g} / \mathrm{m}^{3}$ of $P M_{2.5}$ were detected in display rooms in the Plantin-Moretus museum in Belgium [19], and $40 \mu \mathrm{g} / \mathrm{m}^{3}$ in the Archaeological Museum of Thessaloniki, Greece [12]. If total suspended particles are measured, higher values should be expected, e.g. $60-70 \mu \mathrm{g} / \mathrm{m}^{3}$ inside the Wawel Castle Museum in Cracow, Poland [13]. At this site, particles containing elemental and organic carbon were found to be the ones that penetrate more easily into the museum. Even though particle concentrations in heritage locations are commonly measured in this manner, they tell us little about the fraction of fine particles that penetrate into these locations. Analysis of the bulk chemical composition of the collected particles is a common further step, but it is rare to find more detailed measurements of size distribution including fine particles. A good example are the detailed measurements taken in the Czech National Library in Prague [24], or in some Californian museums [25] which display a clear bimodal size distribution (Figure 1).

The indoor/outdoor ratio ( $\mathrm{I} / \mathrm{O}$ ratio) is widely used to describe the differences between the indoor and the outdoor environments [52-55]. There is a great variability in the measured PM I/O ratios in particular cases, but in general, some rules of thumb can be extracted from experience. Firstly, as shown in Figure 5, the I/O will be higher for particles of size between $0.1-1 \mu \mathrm{m}$. An explanation for this phenomenon is given by the aerodynamics of these particles, and will be further explored in the next sections. Secondly, I/O ratios for particles containing EC (which in urban atmospheres can be understood as DPM), the I/O ratio are typically $0.5-0.9[49,52,56]$.

\section{The life-cycle of fine particles indoors}

Fine particulates penetrate into buildings not only through large openings but also through cracks and filter inlets. At the end of its indoor life, PM deposits on surfaces or is removed by mechanical or natural ventilation. Some particles, especially the larger ones, may

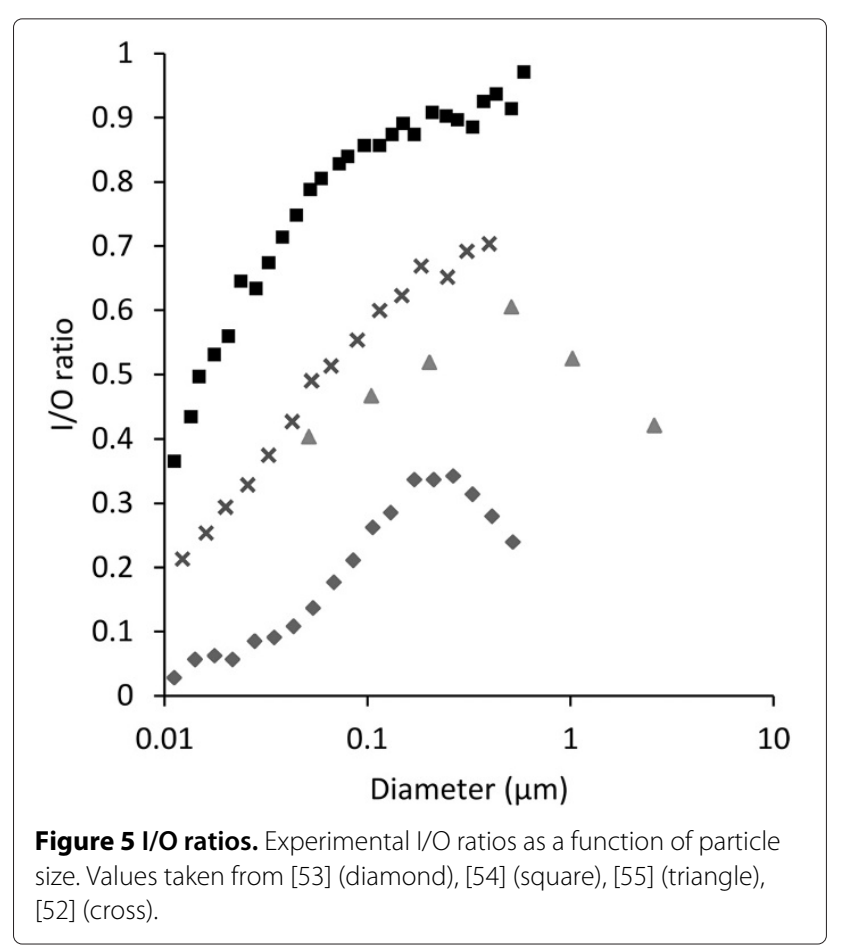


be re-suspended and re-deposited. This set of inlets and outlets of PM summarizes all the steps that ultimately determine the extent of soiling of indoor surfaces. They have been extensively studied as separate phenomena, and considerable literature exists describing each process experimentally, or with empirical or semi-empirical correlations. The work of Nazaroff [57] is the only piece of work presenting a comprehensive summary of all the possible particle flows in any given building. There are other published balances of PM indoors [58], but generally, as they focus mainly on practical health issues, deposition is not studied nor are the minor penetration processes, such as leakage. Also, while health scientists are concerned with the free volume, heritage scientists should be concerned with the room as a whole, and consider both the volume and the surfaces. Figure 6 summarizes, in an approach similar to Nazaroffs, the main particulate matter fluxes in a room.

\section{Penetration}

First and foremost, particles enter through main inlets: windows, doors, and any openings that connect the indoor and outdoor environments, such as gaps under doors. The use of windows for ventilation can quickly increase the particle concentration indoors to match the outdoor levels [59] for all particle sizes. For example, a study of PM in Californian museums [60], such as the Sepulveda house, which lacks an air filtration system,

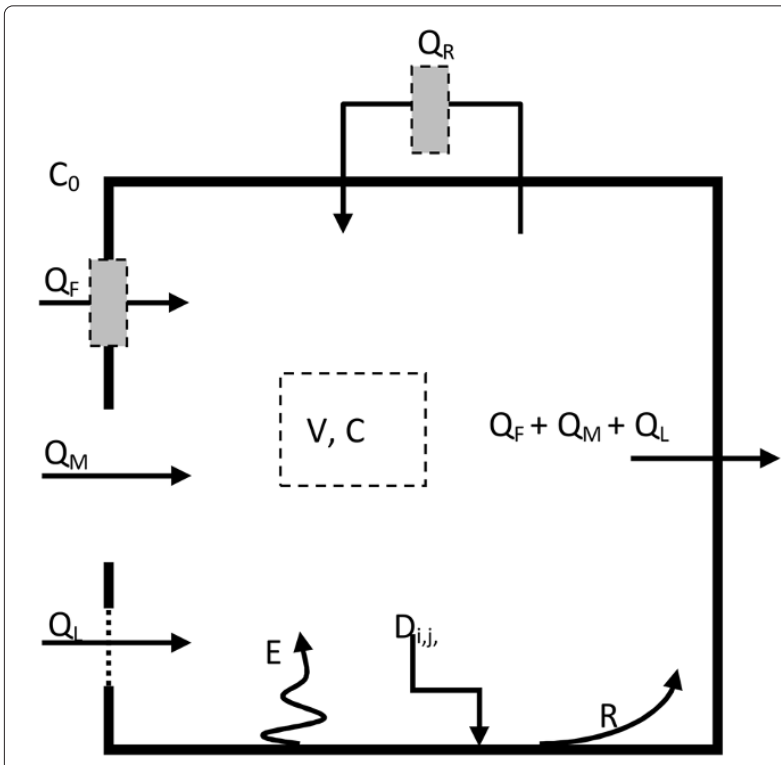

Figure 6 Summary of particle fluxes indoors. The possible inlets and outlets of particles. $Q_{M}$ is a main inlet, such as an open window, $Q_{L}$ the leakage, $Q_{F}$ the filtered inlet, $Q_{R}$ an internal filtered recirculation, $E$ the internal emission, $R$ the re-suspension, $D_{i j k}$ the deposition to walls, floor, and ceiling, $C_{n o}$ and $C_{n}$ the outdoor and indoor concentrations of every particle size fraction, and $V$ the room volume. Both $Q_{F}$ and $Q_{R}$ are subject to certain efficiency. showed I/O rates equal to 1 . This implied that the risk of deposition indoors was equal to the one outdoors. Leakage, or the penetration of particles through cracks or gaps in building envelopes, has also been extensively studied both experimentally and theoretically. It is usually a major particle source in buildings that rely solely on mechanical ventilation [61]. The fundamental difference between a crack and a large opening is that a significant fraction of particles will deposit on the internal surfaces of the crack, and therefore leakage has a certain penetration efficiency which depends on particle size. Ultrafine particles led by Brownian motion will tend to deposit on crack walls, and coarse particles will also deposit quickly on upward facing surfaces [57]. Only the accumulation mode $(0.1-1 \mu \mathrm{m})$ will cross the crack efficiently. Liu and Nazaroff [62] developed a simple mathematical model to estimate the penetration efficiency of particles, and it has been successfully used in several experimental studies since then [63,64]. Figure 7 shows a solution of the Nazaroff equation. Note that the particles between $0.1-1 \mu \mathrm{m}$ penetrate with an almost 100-\% efficiency through the crack. Although generally regarded as a minor source, crack infiltration has been found to account for $73 \%$ of the $P M_{1}$ indoors in a poorly ventilated building [65]. Leakage can lead particles to the interior of showcases. The comparison of particle size distribution inside and outside a display case in a museum in Padova, Italy, revealed that the I/O ratio was 1 for all particle sizes, except for particles larger than $1 \mu \mathrm{m}$ [66], which is in accordance with the theory.

\section{Indoor emission}

Indoor sources of fine particles are found in some specific heritage environments, such as in-use churches where

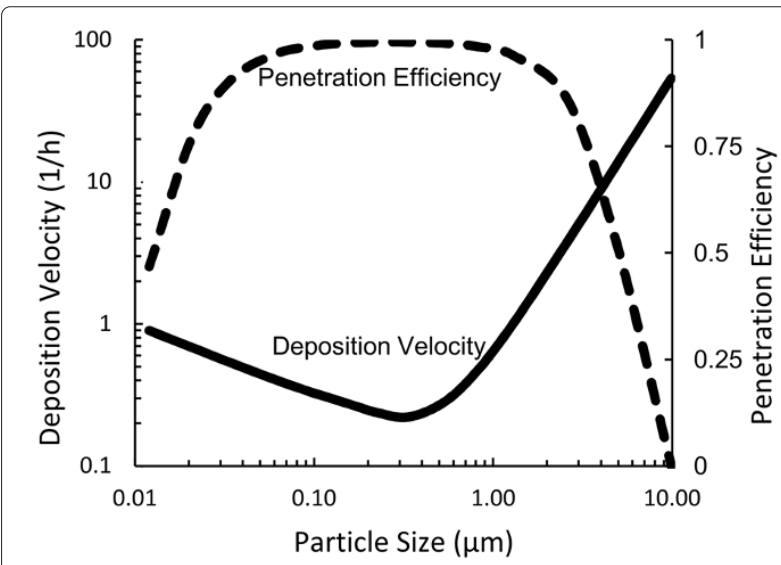

Figure 7 Leakage through cracks. Comparison of deposition and penetration through cracks and leaks obtained with the Nazaroff equations for deposition and leakage. Note that the particles with smaller deposition rates also penetrate through cracks more efficiently. Crack dimensions: width $=0.20 \mathrm{~mm}$, length $=4 \mathrm{~cm}$, pressure difference $=4 \mathrm{~Pa}$, air flow conditions: $\mathrm{K}=0.5$, cubic room $(3 \times 3 \times 3 \mathrm{~m})$. All values taken as representative of realistic cracks by [62] 
incense and candles are burned. An increase for a factor of 9.1 in the concentration of $P M_{1}$ has been found after services that involved incense burning in Ruhr, Germany. In this case, the concentration inside the church remained above the outdoor levels for $\sim 24 \mathrm{~h}$ approximately [67]. These findings are consistent with values found during services in medieval churches in Cyprus, where indoor $P M_{0.5-1}$ concentration was found to be up to 10.7 times larger than the outdoor concentration.

A relatively unknown indoor source is the thermal desorption of organic compounds and emission of submicron particles from household dust $[68,69]$. At temperatures above $50{ }^{\circ} \mathrm{C}$, which are often present in indoor environments, concentrations around 2500 particles $/ \mathrm{cm}^{3}$ can be generated [69]. Investigation of this phenomenon, which to the best of our knowledge has not been researched in heritage sites, should be considered when introducing new heating points in the environment.

\section{Movement \\ Air transport}

The airflow in an indoor space, isolated from the outdoor climate, is governed predominantly by two factors: temperature gradients and mechanical mixing. In a totally isolated room, only the temperature profile will define the air velocity pattern. Studies of indoor micro-climates show that temperature gradients are a consequence of a number of factors such as presence of heating points, proximity to windows, temperature of the surrounding spaces, human presence, lighting or similar. Heat sources induce vertical convective flows that displace contaminants upwards in an enclosed space. Cool vertical surfaces, such as windows, induce downward flows, which results in a circular movement of air around the room. A typically observed air movement pattern is the upward flow from radiators or air circulation behind furniture or paintings due to the difference of temperature between the wall and the air [70]. PM is largely transported by the movement of the surrounding air. In other words, the Stokes number, the nondimensional parameter which describes the behaviour of particles in suspension, is generally well below 1 (St $<<$ $1)$. The Stokes number, $S t=\tau U / D$, is determined by the ratio of the relaxation time of the particle $(\tau)$, the characteristic dimension of the obstacle obstructing the fluid flow $(D)$ and the velocity of the fluid $(U)$.

Particles with St $>1$ will have their own velocity field and enough inertia to detach from air streamlines, and particles with St $<1$ follow the air current closely [71]. However, the velocity field of particles does not coincide completely with the velocity field of air. Particles have a certain mass, and therefore their velocity has a vertical component due to gravitational settling. Coarse particles settle down gravitationally much faster than fine particles, and this creates a certain stratification of the concentration. Measurements in indoor domestic environments have revealed a higher proportion of $P M_{2.5}$ on the upper parts of rooms, and higher abundance of $P M_{10}$ towards the floor [51]. Measurements of particle deposition in ceiling, walls and floor reveal that almost no coarse particles deposit on the ceiling, while all the deposited mass in the floor is due to coarse particles [25].

\section{Other transport mechanisms}

The smallest particles are largely affected by Brownian diffusion (also called "random walk"), which is a result of collisions between particles and air molecules and occurs in all directions. In any given room, coarse particles will be found in areas with the highest air flow, while fine particles will tend to diffuse around all the available space. Thermophoresis, the displacement of particles from high to low temperatures, is a phenomenon also common indoors. The balance between air transport, diffusion and thermophoresis has been studied in detail by Camuffo [72] in the case of the soiling of murals. It was pointed out that when a vertical fresco is colder than the surrounding air, the temperature gradient forces thermophoresis towards the wall, and at the same time a downward freeconvection flow develops, resulting in an overall increase of deposition rates. When a fresco is warmer than the air thermophoresis takes fine particles away from the wall, but this effect may be counteracted by an upwards convective flow that increases deposition of coarse particles. The best situation for conservation purposes is, therefore, a thermal equilibrium between wall and air, whereas cold walls are the less desirable scenario.

\section{Deposition}

The deposition velocity of PM varies with particle diameter. This dependence is well known, and several authors have suggested mathematical expressions to estimate deposition velocities under different conditions. Perhaps the most used is the model derived by Nazaroff et al. $[73,74]$, which has been successfully applied to museum environments [75]. Figure 8 has been obtained by solving this model, and shows the range of values of deposition velocity that can be expected under different flow conditions and for different diameters.

\section{Dependence on particle diameter}

The highest deposition rates are found for the largest particles $(1-10 \mu \mathrm{m})$, which are governed mostly by gravity and tend to deposit on horizontal surfaces, and for the smallest particles $(0.01-0.1 \mu \mathrm{m})$, which are mostly governed by Brownian motion and tend to diffuse and collide against floor, walls or ceiling. The mass of particles is only relevant in the larger size fraction, in which larger densities mean larger deposition velocities. Between these two size modes, the accumulation mode $(0.1-1 \mu \mathrm{m})$ shows the 


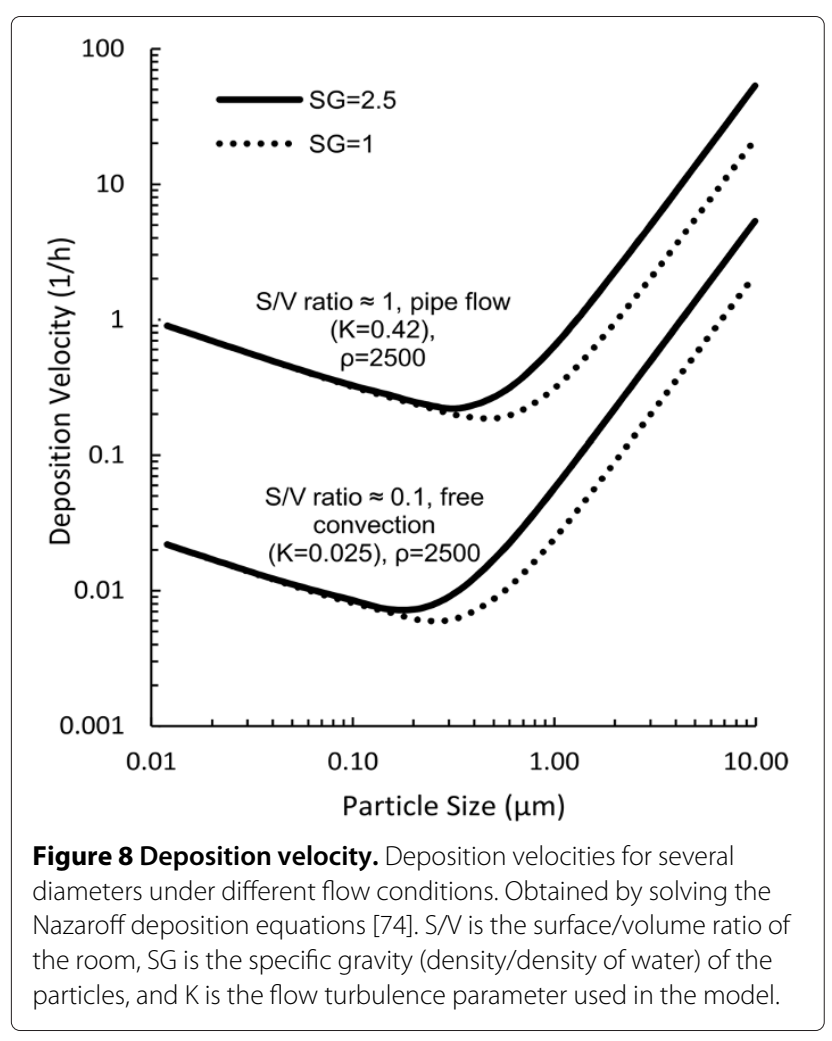

slower deposition rates, which are up to 2 orders of magnitude smaller than that of the coarse particles [57]. These lower deposition rates imply that particles in the accumulation mode tend to remain in suspension for longer, and therefore travel longer distances. In other words, while the coarse particles will deposit shortly after penetration indoors, near the source, the accumulation particles will distribute more evenly around the available space [76].

\section{Dependence on air flow}

The flow turbulence parameter, $K$, a key component of the Nazaroff deposition model, represents the turbulence regime of the air. It is an influential parameter and at low values of $K$, when turbulence is low and air is, for example, driven by temperature differences that generate free convection, particles display the lowest deposition rates. The deposition rates for all diameters increase with higher air velocities, which can be produced by wind or mechanical ventilation. Deposition rates are also smaller when the surface to volume ratio of the room is small, i.e. when the room has a small surface in relation to its volume. As a general rule, small volumes such as display cases and boxes will have larger $\mathrm{S} / \mathrm{V}$ ratios than large galleries, but one should bear in mind that the number of objects (e.g. furnishings and exhibits) present in the room will also increase the S/V ratio, and thus increase deposition. Similarly, the roughness of surfaces favours deposition [76].
The applicability of the Nazaroff deposition model has been extensively proven in experimental investigations of particle deposition in a range of environments [77,78], rough surfaces of different materials [79], rooms with fans, and furnished or unfurnished rooms [80].

\section{Re-suspension}

Once deposited, PM is adhered to surfaces by adhesion forces that can be orders of magnitude higher than gravity [71], and of which Van der Waals adhesion is the most relevant [81]. Changes in air flow conditions can eventually compensate these adhesion forces and re-suspend the deposited particles. Re-suspension rates are strongly dependant on particle diameter. Larger particles are resuspended more easily. In some museum environments, particles of $>1 \mu \mathrm{m}$ appear only during museum opening hours due to re-suspension caused by visitors. These particles redeposit gravitationally as soon as the museum is closed [17]. This type of behaviour has been studied for a long time, and common indoor activities such as walking and vacuum cleaning have been associated with re-suspension of particles $>1 \mu m$ [82], and have been found to increase particle concentrations up to 7 times the background concentration [83]. Re-suspension due to inappropriate cleaning habits has been found to account for the spatial distribution of particles in a monastery which displayed an otherwise very stable indoor environment [84].

This mechanism is very dependent on particle size, and $<1 \mu m$ particles are rarely affected. Furthermore, resuspension affects only those particles that are deposited on the floor or the objects involved in the human activity that causes it, such as furniture. The fraction of fine particles involved in the deposition and re-suspension cycle could be expected to be negligible, although there appears to be no relevant experimental research about resuspension of the accumulation size mode. Nonetheless, re-suspension is a phenomenon that has been extensively modelled [85-87], and it is possible to assess the re-suspension rates of fine particles mathematically.

Figure 9 shows the solution of one of these models, the empirical correlation recommended by [88], along with deposition rates calculated with the Nazaroff equation. A friction velocity of $1 \mathrm{~m} / \mathrm{s}$ has been used, a relatively high air velocity for an indoor environment which may represent an extreme situation, e.g. the opening of a window with a strong air current. Note that particle re-suspension decays exponentially with time since the moment in which the re-suspending event begins. Consequently, even though re-suspension might exceed deposition when air starts moving, the re-suspension rate rapidly decreases below the deposition rate. The overall particle flux is positive towards surfaces. It can be concluded that as an approximate guideline, re-suspension rates for 


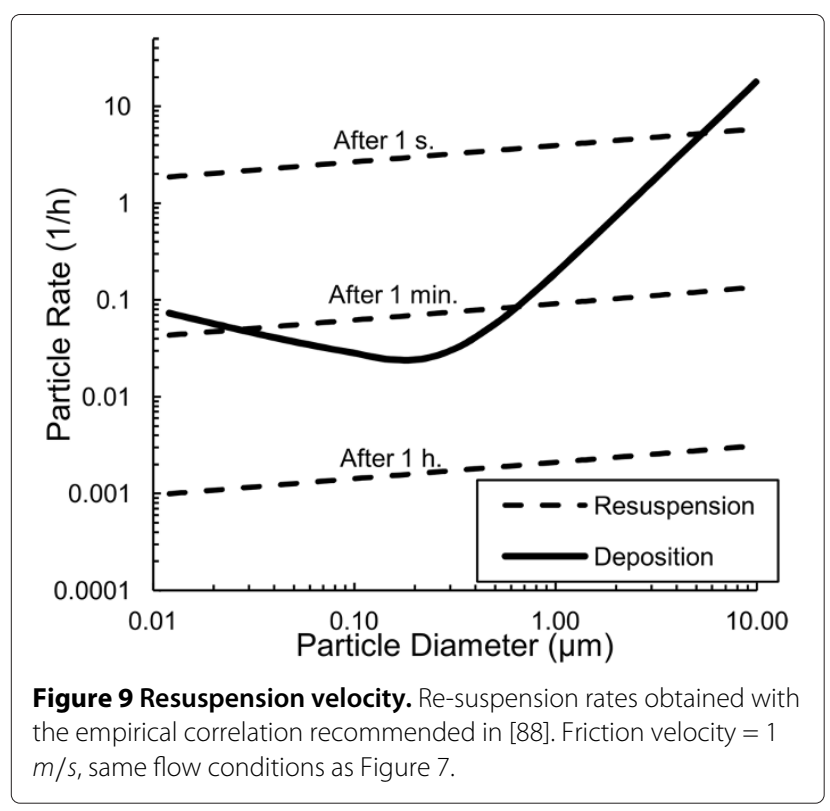

submicron particles indoors will be orders of magnitude smaller than deposition rates, unless air speed is subject to frequent fluctuations due to wind or mechanical ventilation.

\section{Coagulation}

Some authors attribute the measured particle decay in experimental conditions exclusively to deposition while others do to coagulation as well [89]. Naturally, the fraction of particles in a given size fraction that collide or deposit depends largely on the number of particles and on the proportions of the room, specifically on the surface/volume ratio. In some cases either the former or the latter process may be negligible. But in broader terms, it is clear that the temporal evolution of particle number concentration cannot be fully understood without taking both processes into account. In a small chamber with a high concentration of diesel particles (from $8.11 \times 10^{5}$ to $84.3 \times 10^{5}$ particles $/ \mathrm{cm}^{3}$, which compares to the range of $1 \times 10^{5}$ to $7 \times 10^{5}$, concentrations which can be found in street canyons in Stockholm [90]), with diameters from 15 to $670 \mathrm{~nm}$, particle size increased up to a factor of $2.6 \mathrm{dur}-$ ing the experiment due to coagulation [91]. An increase of particle size up to $60 \%$ has been also found in the case of tobacco smoke during the first $30 \mathrm{~min}$ after smoking a cigarette [92]. However, it is rare to find such high concentrations in indoor environments. It has been experimentally demonstrated that coagulation can be neglected in comparison to deposition when total suspended particles (TSP) concentration is under $1 \times 10^{3}$ particles $/ \mathrm{cm}^{3}$, and for ultrafine particles $(<0.1 \mu \mathrm{m})$ it is only relevant above $1 \times 10^{4}$ particles $/ \mathrm{cm}^{3}$. While particle deposition occurs at a constant rate independent of the particle number, coagulation is a second order process that depends on the square root of particle number concentration. This is described by the following equation [93]:

$$
\frac{\delta n}{\delta t}=-K n
$$

where $n$ is the particle number and $K$ the coagulation constant. The difference in behaviour (linear for deposition and quadratic for coagulation) allows us to appreciate the effect of both processes on particle decay. Other authors have acknowledged the importance of coagulation as a relevant removal process. It has been found to account for up to $80 \%$ of particle loss in a small chamber $\left(1.6 \mathrm{~m}^{3}\right)$ with steady air, with deposition removing only from 10 to $15 \%$ of the paper ash particles used (average particle diameter of $0.069 \mu \mathrm{m}$ ). This situation changes under stirring, in which case deposition may account for $50 \%$ of the removal in the beginning of the experiment and up to $90 \%$ at the end [89], as coagulation rate gradually reduces as particle number decays. These results are in agreement with [94], where it was estimated that coagulation could remove from $40 \%$ to $70 \%$ of the environmental particles in a street canyon with a low wind speed $(2 \mathrm{~m} / \mathrm{s})$ and around $20 \%$ at higher wind speeds $(8 \mathrm{~m} / \mathrm{s})$, and with the experimental results of [95], who found high coagulation rates in rooms with low air exchange rates. All the mentioned studies focus on particles smaller than $1 \mu \mathrm{m}$, since the smallest particles are more likely to coagulate, not only because of their higher mobility, but because they are typically present in higher number concentrations [73]. Coagulation is known to be fairly independent of particle composition and air relative humidity [96]. There is litthe doubt that coagulation is a relevant removal process in enclosed or semi-enclosed and highly polluted environments [97], but it is also true that it may be negligible in most heritage environments.

\section{Filtered removal}

PM can be removed using a filtration system. There are a number of filter configurations. Air inlet and outlet can be both filtered, or air can be filtered and recirculated into the room in a closed system. The efficiency of such filters is well known and its calculation as a function of particle size is standardised throughout the industry. Commonly, efficiency is expressed using the Minimum Efficiency Reporting Value (MERV) ranging from 1 - 20, 1 - 4 being common values for domestic filters capable of retaining only the largest particles $(>10 \mu \mathrm{m})$ and 17 - 20 are typical values for fine filters used in pharmaceutical or electronic applications, capable of retaining submicron sized particles $(<0.3 \mu \mathrm{m})$, Figure 10 shows the efficiency of some American Society of Heating, Refrigerating and Air-Conditioning Engineers (ASHRAE) rated 


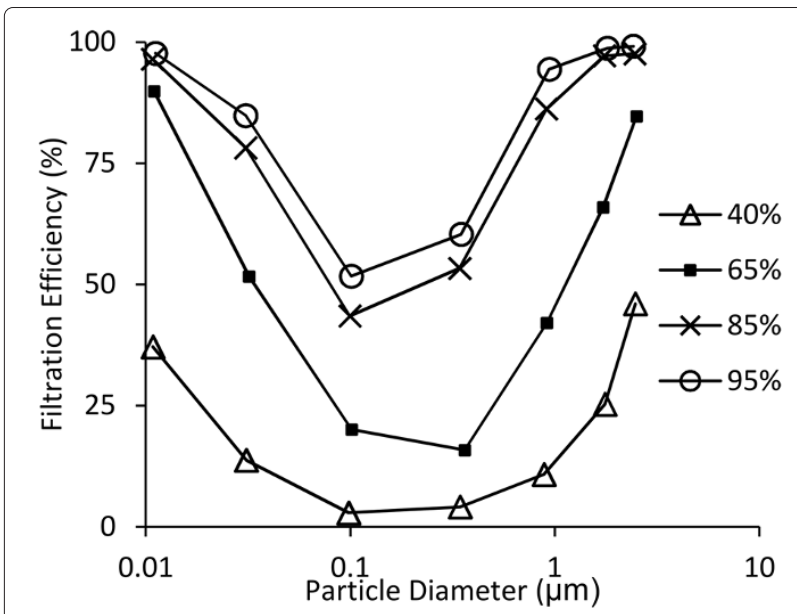

Figure 10 Examples of filter efficiency curves. Efficiency of four ASHRAE-rated filters of different average efficiencies operating at 1.3 $\mathrm{m} / \mathrm{s}$, adapted from [98].

filters [98]. The ASHRAE recommends museums using filters with a MERV from 7 - 11 [99]. Particle filtration is governed by the same physical mechanisms as infiltration through cracks, thus the expected removal efficiency for each particle size will be inversely proportional to the particle penetration factor. As discussed, fine particles deposit through Brownian diffusion and coarse particles are easily intercepted by impaction, while the accumulation mode exhibits the lowest removal efficiency. It is also worth remarking that an increase of air flow rate will improve the removal of fine particles, but would be less effective as particle size increases, as larger particles are less affected by airflow. The accumulation mode of DPM are the particles, which are removed less efficiently by ventilation systems.

\section{The consequences of deposition of fine particles}

Deposition is a three-fold problem. First, mere deposition (or "dry" deposition) can cause area coverage and have a visual effect on the soiled object, a "visual nuisance", as it has been qualified in some of the most relevant investigations [100,101]. Secondly, frequent or intense cleaning might have a negative effect on the underlying surface, as well as being a cost-intensive process. And finally, the deposited particles might interact chemically with the surface, creating a damage layer and producing irreversible degradation. Although evidence exists for all these phenomena, research has prioritized soiling on outdoor surfaces and particularly layers produced on stone. The following section attempts to describe these three processes indoors -visual nuisance, chemical damage and damage by cleaning- based on the understanding that evidence is scarce, and in some cases conclusions must be extracted from evidence obtained in outdoor experiments.

\section{Soiling indoors}

Figure 11 may convey a sense of the time-scale of soiling processes. It shows experimental values adapted from different publications of the percentage of reflectance lost during environmental exposure. Due to the lack of experimental data on soiling indoors, some sheltered cases are included. The time needed to achieve a $10 \%$ loss of reflectance, which corresponds approximately to a change visible by the naked eye [102], is highly variable and ranges from a month to a year. Note also that all soiling processes occur at a varying rate, which tends to be higher during the first weeks of exposure [4,103-107]. This nonlinear behaviour is what equations (2), (3) and (4) attempt to reflect.

Soiling is generally assumed to be directly proportional to the loss of reflectance and lightness (or increase in haze) of a material. Several models for soiling are currently under discussion. Historically, the first dose-response functions were developed under the assumption that soiling is proportional to the square root of the concentration of PM.

$$
\frac{\Omega}{\Omega_{0}}=k \sqrt{C_{P M} t}
$$

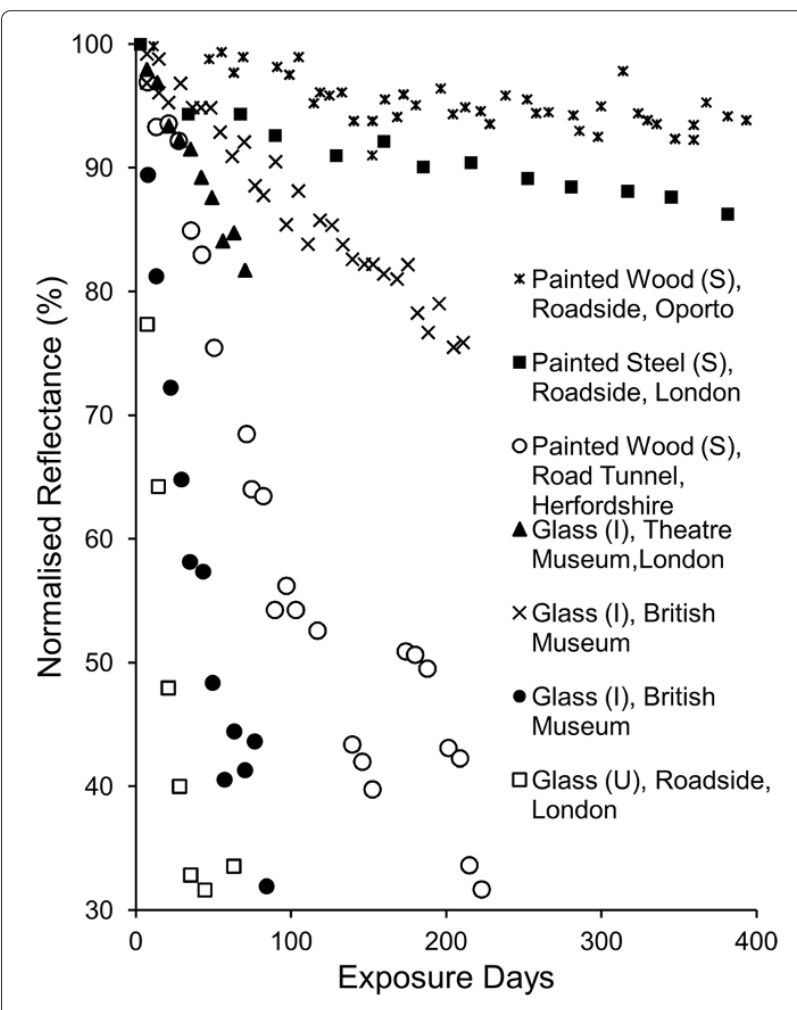

Figure 11 Collection of soiling measurements using reflectance. Experimental values of loss of reflectance. $S=$ sheltered, I = indoors, $U=$ unsheltered. Data adapted from [103] (Oporto), [4] (roadside, London), [105] (road tunnel, Hertfordshire), [106] (theatre museum, London), [104] (British Museum, London) and [107] (unsheltered roadside, London). 
where $\Omega$ is an optical property and $\Omega_{0}$ its initial value, $k$ is a "soiling constant", $t$ is the elapsed time and $C_{P M}$ is the concentration of PM in the surrounding air. This model was first proposed by Beloin and Haynie in 1975 [108] and has been significantly endorsed by several researchers $[10$, $103,109]$. The second model, also widely used, follows an exponential relation in the form:

$$
\frac{\Omega}{\Omega_{0}}=\exp \left(k C_{P M} t\right)
$$

which was firstly suggested by Mansfield and Hamilton in 1989 [110] and has also been extensively used [4,111,112]. For some comparisons and critical assessment of these models see $[103,104]$. Lastly, the most recent research suggested the use of the Hill equation for the development of dose-response functions:

$$
\Omega_{t}=B+\frac{K}{1+(M / t)^{H}}
$$

where $B, K, M$ and $H$ are constants that define the varying response of soiling with time (see [113] for a detailed explanation). This model has been fitted to experimental data by Lombardo and Ionescu at different occasions $[114,115]$ and has been tested with data collected during the MULTI-ASSESS project [116] in different European locations. A second discussion relates to which concentration should be used as $C_{P M}$. Some authors have suggested total suspended particles, while others have used $P M_{2.5}$, $P M_{10}$, DPM or particulate elemental carbon (PEC), given that most of the soiling is due to traffic-generated particulates [110].

\section{Cases of soiling indoors}

Soiling outdoors is popularly associated with black stains on faades, while soiling indoors is mostly associated with the deposition of household dust, i.e. coarse particles. In effect, experimental and observational studies are markedly biased towards outdoor blackening and indoor dust, perhaps due to the experimental difficulties of discerning different particle sizes of indoor deposits, especially the smallest. However, it is not difficult to find examples of well visible deposition of fine combustion particles. Some notable examples are found at induction and ventilation outlets [117] or on the murals of a palace in Padova, where inconveniently placed radiators were causing heavy soiling by dust and soot [118]. The darkening in the centre of the murals in Michelozzo's Courtyard, Florence, Italy, has been attributed to deposition of trafficgenerated particles, since measurements of $P M_{2.5}$ display a high proportion of organic and elemental carbon [18]. In some occasions, the damage layers related to the deposition of combustion particles are related to the past use of the building, and not to modern traffic emissions e.g. in the Buddhist statues of the Yunguang Grottoes, China [119].

\section{"Ghosting": a particular deposition event}

A specific indoor discoloration event related to heating points and the presence of semi volatile organic compounds (SVOCs) has been repeatedly reported in the literature under various names, which include "ghosting" [120] , "black magic dust" [121] and "fogging" [122]. Even though there have been no specific mentions of the phenomenon in a heritage context, it is clearly not exclusively found in dwellings "ghosting" deposits differ from dry deposition by the presence of droplet-like particles, and a layer of condensed SVOCs [123]. The phenomenon is triggered only under certain conditions: emission of SVOCs (e.g. from refurbished materials), low ventilation rates, high temperature gradients (e.g. above lamps or radiators), and, naturally, the presence of PM. The dark appearance of stains is caused by the presence of elemental and organic carbon agglomerates, but coarse dust particles rich in $\mathrm{Ca}$ and Fe can be present as well [123]. Even though efforts have been made to isolate the causes that can initiate this soiling event, all attempts to reproduce it in experimental conditions have been unsuccessful [124].

\section{Visual consequences}

The small size of fine particles has two implications that should be stressed in any discussion of their visibility: their small covering area and their light scattering properties. In fact, an important fraction of fine PM is smaller than the wavelength of light visible to humans $(\sim 390$ $750 \mathrm{~nm}$ ). This, however, does not mean that particles cannot be seen when they accumulate on a surface. Firstly, if enough particles are deposited, the deposit will become visible even if a single particle cannot be seen. For example, candle soot deposits are common, even if the size of particles emitted from a burning candle ranges from 10 - $100 \mathrm{~nm}$ [125]. Secondly, fine particles do not deposit alone, and all analyses of deposits have found a certain size distribution. Beyond that remark, it can be added that particles with diameters below the visible range can still scatter light when in suspension or when deposited on transparent materials through scattering in the Rayleigh regime. Several investigations report refractive indices for particles or soot small in comparison with the wavelength of light $[126,127]$. These aspects; however, have not been researched in the context of heritage science.

While perceivable visually, the effects of soiling are quite difficult to quantify. Recently, attempts have been made to identify thresholds between acceptable and unacceptable levels of soiling on building faades. However, the relations between perception and soiling are complex, as the reaction of the public is not simply proportional to the amount of matter deposited. Soiling can be perceived in some cases as patina, and to a certain degree, it can enhance the appearance of a building [128]. The perceived degree of soiling is also influenced by the cleanliness of the 
surrounding environment. Despite these issues, Brimblecombe et al. [100] used on-site questionnaires to identify soiling levels that are publicly unacceptable. Their results show that the public perception measured in terms of perceived lightness is fairly consistent with the perceived need for cleaning and could be used to define threshold doses in terms of environmental particle concentration. Another study [129] shows that soiling is perceived as negative when it interferes with architectural shapes. However, these studies are focused on the darkening of building features outdoors, and it can be argued that they have a limited applicability to indoor deposition.

Some researchers have left aside the complexities of aesthetic judgement, and have concentrated on the limits on the perception of soiling. Bellan et al. [60] have measured the human eye ability to detect soot deposition on flat, plain colour surfaces using printed dots $(60-160 \mu \mathrm{m})$ on white and coloured matte surfaces. Their results show that some observers are able to discern a soiled surface from a clean one when the covered area is just a bit higher than $1 \%$ of the total, and that deposition becomes obvious to all at around 9\% coverage. The perceptive ability is improved if the soiled surface is observed alongside a clean one, in which case all observers identify soiling when just $3.5 \%$ of the area is covered. Experiments with larger dots $(0.5-1$ $\mathrm{mm}$ ) have led to a threshold of $0.2 \%$ area coverage [102]. These results have been of great use for the establishment of guidelines and recommendations, e.g. by [130], since they provide a threshold value in terms of area coverage. But it must be noted that the diameters used in the experiments correspond with the coarser dust rather than with "soot" or fine particles, for which no direct account of their thresholds for visibility has been published.

Recently, Druzik and Cass claimed that some specific paintings were under special risk of soiling [131]. Particularly paintings with large colour fields, like those by Mark Rothko or Franz Kline, were assessed as being more vulnerable to the aesthetic damage due to soiling.

\section{Degradation of soiled objects}

It has long been established that particulate pollution from road traffic contributes greatly to the degradation of stone outdoors. The presence of DPM has been related to the decay of carbonate [132] and silicate stones [133]. Also outdoors, several corrosion products of copper were identified on statues where soot was also present [134], but no formal relation was established. Although the effects on materials other than stone are less investigated, it can be expected that the reactive components of DPM will also interact with materials, which are typically displayed and used indoors, such as paper, paint and varnishes, or textiles.

There is an important lack of literature about the effects of particulate deposition on the surface of paper, leather, textiles, paintings, varnishes and other materials typically found indoors, perhaps due to the complexity of the problem and the great variety of materials involved. A brief list of potential degradation pathways related to particle deposition is available in the literature [17]: (i) S-rich material (such as DPM, which contains oxidised sulfur compounds [41]) can cause discolouration of paintings; (ii) ammonium sulfate can induce bloom on varnish. Ammonium sulfate is a "secondary aerosol" (i.e., formed in the atmosphere), but it often coexists (and even aggregates) with carbonaceous particles [135]; (iii) The presence of $\mathrm{CaSO}_{4}$ favours the adsorption of soot; (iv) Fe-Rich particles can catalyse the oxidation of $\mathrm{SO}_{2}$ to $\mathrm{H}_{2} \mathrm{SO}_{4}$. Aged diesel particulate matter is hygroscopic [136], and therefore can favour the adsorption of water that accelerates hydrolitic and oxidative processes, leading to fading of pigments, and degradation of paper and textiles [11]. Despite the lack of systematic investigations, the effects of fine PM deposition have been repeatedly noted by conservators. Damage layers related to black carbon deposition have been detected on indoor murals and wall paintings [137], and on polychromy [138]. The word "black crust" is sometimes used to describe these damage layers found indoors, but it is a macroscopic assessment that gives very little information about the origin of degradation.

Conclusions may be extracted from studies carried out with particles of similar composition. The corrosion of zinc and steel has been studied in relation to the presence of deposited particles derived from the combustion of oil (which may be comparable to diesel fuel) and coal [139]. The authors concluded that in relatively unpolluted atmospheres inert particulates can induce corrosion in zinc and mild steel due to differential aeration, an effect which is masked when the overall corrosion rates increase. Oil-ash particles were also found to be much more corrosive than coal-ash particles. Although far from the heritage field in terms of temperature and concentration, some investigations have demonstrated that DPM leads to severe degradation of ceramic filters used in engine exhaust tubes [140].

\section{Cleaning}

Cleaning of soiled surfaces can induce undesired degradation. It is well known that cementation of coarse dust increases the difficulty of removal [141]. DPM behaves in a similar way, due to its ability to penetrate into pores and its potential chemical interaction with the surface. The National Trust's Manual of Housekeeping states that dry cleaning methods, such as brushing, vacuum cleaning, or even the use of erasers, might be insufficient, and that the deposition of soot can produce "disfiguring, virtually indelible staining" [142]. In cases of extreme soiling, it has been reported that vacuuming removes only the loose deposits of smoke particulates, and that wiping may 
further attach particles to porous surfaces [143]. These difficulties have prompted the use of laser cleaning methods; however, laser removal of particles from organic materials have been found to result in yellowing of the underlying surface $[144,145]$.

\section{Conclusions}

There is a certain ambiguity of the terms used to describe indoor PM in the heritage literature. There has been some discussion on how the staining of façades should be described (black crust formation, staining, darkening, blackening, soiling) $[100,146]$ but this discussion has not taken place for indoor heritage. As a consequence it is not clear what the word "soot" refers to in some cases. It can refer to carbon-based agglomerates in suspension, or the same particles deposited on a surface, or a black stain of unknown composition but of "carbonaceous" appearance, which might also be only a surface deposit. There is a need for the development of a more accurate terminology that makes a clear distinction between suspended fine particles (DPM, combustion-derived or even soot), dry deposition of these particles without further effects and removable with cleaning (which could be called darkening, or soiling), and the degradation layer formed due to the interaction of the deposit with the underlying surface.

PM monitoring in heritage sites is generally focused on coarse dust, and the two most frequently measured particle types are $P M_{10}$ and $P M_{2.5}$, which include particles up to 2.5 and $10 \mu \mathrm{m}$. This standard, however, has limitations. Measurements of $P M_{2.5}$ sum up some particles from the coarse mode $(>1 \mu \mathrm{m})$ and some from the fine mode $(<1 \mu \mathrm{m})$ and therefore these values do not help to identify the fractions of fine and coarse particles, which would enable appropriate action to be taken. Complete size-resolved measurements of particle concentration would provide more information on the likely source and typology of particles; however, measurement of size distributions requires costly equipment. A much more informative and cost-effective measurement would be $P M_{10}$ and $P M_{1}$, or $P M_{10-1}$ and $P M_{1}$. In a heritage site situated in an urban environment, for example, these values would provide a useful estimate of particles as a consequence of traffic emissions that penetrate into the building.

The formation of black stains in the presence of SVOCs ("ghosting"), or the emission of fine and ultrafine particles when indoor dust is in contact with warm surfaces are phenomena that have been repeatedly observed in indoor environments. It is unknown what the impact of these soiling events is, and whether in some cases they are wrongly attributed to outdoor sources.

Much is known about the aerodynamics of fine PM. The accumulation mode $(0.1-1 \mu \mathrm{m})$, due to its size, displays low deposition rates, low re-suspension rates, and a high penetration efficiency through cracks and filters. Low deposition rates have different implications. Deposition will be a slow process, but it will occur eventually if particles are not removed. They will distribute evenly around the space, depositing far from the source, and will reach areas in walls and ceiling that are difficult to access. Low re-suspension rates, in combination with a small size that favours penetration into porous surfaces, will lead to difficulties with cleaning and irreversible soiling.

Less is known about what occurs after soiling. There is a significant disproportion between the detailed knowledge of the aerodynamics of fine particles, and what is currently known about the chemical effects of the most common particle types and the potential degradation of soiled (heritage) surfaces. The scarce evidence available is just enough to assess that DPM and other particles derived from combustion can have an active role in the degradation of materials beyond soiling. Considering the costs associated with cleaning, it is important to know if removal of deposited fine particles should be a priority. Risk assessment cannot be based solely on the spatial distribution and deposition rates of fine particles. There is a need for research into chemical interactions between the most common fine particulates (DPM and other combustion-derived particles) and different materials that represent indoor heritage surfaces.

\section{Abbreviations}

DPM: Diesel Particulate Matter; EC: Elemental Carbon; I/O: Indoor/Outdoor Ratio; MERV: Minimum Efficiency Reporting Value; OC: Organic Carbon; PEC: Particulate Elemental Carbon; PM: Particulate Matter; SVOCs: Semi-Volatile Organic Compounds; TSP: Total Suspended Particulates; UFP: Ultra-Fine Particulate matter.

\section{Competing interests}

The authors declare that they have no competing interests.

\section{Authors' contributions}

JGB critically analysed the literature and drafted the manuscript, MS co-drafted the manuscript. Both authors co-conceived of the study, participated in its design, read and approved the final manuscript.

\section{Authors' information}

JGB is a PhD candidate at the UCL Centre for Sustainable Heritage. His research focuses on CFD modelling of fine and ultrafine particulate matter in indoor heritage environments.

MS is Senior Lecturer in Sustainable Heritage at the UCL Centre for Sustainable Heritage and Course Director of the new MRes Heritage Science at the Centre. His research focuses on the development of new scientific tools and methods of study of heritage materials, collections and their interactions with the environment, particularly development and use of damage functions and integrated modelling of heritage collections. Presently, he is the Principal Investigator of the UK AHRC/EPSRC Science and Heritage Programme project Collections Demography (2010-2013) and a Co-Investigator on Heritage Smells! (2010-2013). In 2008, he co-coordinated the 8th European Conference on Research for Protection, Conservation and Enhancement of Cultural Heritage.

Received: 11 February 2013 Accepted: 1 March 2013

Published: 3 April 2013 


\section{References}

1. Ghedini N, Ozga I, Bonazza A, Dilillo M, Cachier H, Sabbioni C: Atmospheric aerosol monitoring as a strategy for the preventive conservation of urban monumental heritage: The Florence Baptistery.. Atmos Environ 2011, 45(33):5979-5987. [http://linkinghub. elsevier.com/retrieve/pii/S1352231011008090]

2. Horemans B, Cardell C, Bencs L, Kontozova-deutsch V, Wael KD, Van Grieken R: Evaluation of airborne particles at the Alhambra monument in Granada, Spain. Microchem J 2011, 99(2):429-438. [http://dx.doi.org/10.1016/j.microc.2011.06.018]

3. Monforti F, Bellasio R, Bianconi R, Clai G, Zanini G: An evaluation of particle deposition fluxes to cultural heritage sites in Florence, Italy. Sci Total Environ 2004, 334-335:61-72. [http://www.ncbi.nlm.nih.gov/ pubmed/15504493]

4. Watt J, Jarrett D, Hamilton R: Dose-response functions for the soiling of heritage materials due to air pollution exposure. Sci Total Environ 2008, 400(1-3):415-424. [http://www.ncbi.nlm.nih.gov/pubmed/ 18774161]

5. Karaca F: Mapping the corrosion impact of air pollution on the historical peninsula of Istanbul. J Cultural Heritage 2012. Article in press. [http://www.sciencedirect.com/science/article/pii/S129620741200091X]

6. de la Fuente D, Vega JM, Viejo F, Díaz I, Morcillo M: City scale assessment model for air pollution effects on the cultural heritage.. Atmos Environ 2011, 45(6):1242-1250. [http://linkinghub.elsevier.com/retrieve/ pii/S1352231010010368]

7. Camuffo D, Bernardi A: Controlling the microclimate and particulate matter inside the historic anatomy theatre, Padua. Mus Manage Curatorship 1996, 15(3):285-298. [http://www.tandfonline.com/doi/abs/ 10.1080/09647779709515489]

8. Spolnik Z, Worobiec A, Samek L, Bencs L, Belikov K, Van Grieken R: Influence of different types of heating systems on particulate air pollutant deposition: The case of churches situated in a cold climate.. J Cult Heritage 2007, 8:7-12. [http://www.sciencedirect.com/ science/article/pii/S1296207406001105]

9. Samek L, Maeyer-Worobiec AD, Spolnik Z, Bencs L, Kontozova V, Bratasz L, Kozlowski R, Van Grieken R: The impact of electric overhead radiant heating on the indoor environment of historic churches. J Cult Heritage 2007, 8(4):361-369. [http://www.sciencedirect.com/science/ article/pii/S1296207407001021]

10. Urosevic M, Yebra-Rodríguez A, Sebastián-Pardo E, Cardell C: Black soiling of an architectural limestone during two-year term exposure to urban air in the city of Granada (Spain). Sci Total Environ 2011, 414:564-575. [http://www.ncbi.nlm.nih.gov/pubmed/22153605]

11. Gysels K, Deutsch F, Van Grieken R: Characterisation of particulate matter in the Royal Museum of Fine Arts, Antwerp, Belgium. Atmos Environ 2002, 36(25):4103-4113. [http://www.sciencedirect.com/science/ article/pii/S1352231002002297]

12. Mouratidou T, Samara C: PM2.5 and associated ionic component concentrations inside the archaeological museum of Thessaloniki. N. Greece. Atmos Environ 2004, 38(27):4593-4598. [http://www. sciencedirect.com/science/article/pii/S1352231004004637]

13. Worobiec A, Samek L, Krata A, Meel KV, Krupinska B, Stefaniak EA, Karaszkiewicz P, Van Grieken R: Transport and deposition of airborne pollutants in exhibition areas located in historical buildings-study in Wawel Castle Museum in Cracow, Poland. J Cult Heritage 2010, 11(3):354-359. [http://www.sciencedirect.com/science/article/pii/ S1296207410000221]

14. Hu T, Lee S, Cao J, Chow JC, Watson JG, Ho K, Ho W, Rong B, An Z: Characterization of winter airborne particles at Emperor Qin's Terra-cotta Museum, China. Sci Total Environ 2009, 407(20):5319-5327. [http://www.sciencedirect.com/science/article/pii/ S0048969709006251]

15. Gysels K, Delalieux F, Deutsch F, Van Grieken R, Camuffo D, Bernardi A, Sturaro G, Busse HJ, Wieser M: Indoor environment and conservation in the Royal Museum of Fine Arts, Antwerp, Belgium. $J$ Cult Heritage 2004, 5(2):221-230. [http://www.sciencedirect.com/science/article/pii/ S1296207404000330]

16. Verney-Carron A, Dutot A, Lombardo T, Chabas A: Predicting changes of glass optical properties in polluted atmospheric environment by a neural network model. Atmos Environ 2012, 54(0):141-148. [http:// www.sciencedirect.com/science/article/pii/S1352231012002312]
17. Camuffo D, Brimblecombe P, Van Grieken R, Busse HJ, Sturaro G, Valentino A, Bernardi A, Blades N, Shooter D, De Bock L, Gysels K, Wieser $\mathrm{M}$, Kim O: Indoor air quality at the Correr Museum, Venice, Italy. Sci Total Environ 1999, 236(1-3):135-152. [http://www.ncbi.nlm.nih.gov/ pubmed/10535149]

18. Nava S, Becherini F, Bernardi A, Bonazza A, Chiari M, Garcia-Orellana L, Lucarelli F, Ludwig N, Migliori A, Sabbioni C, Udisti R, Valli G, Vecchi R: An integrated approach to assess air pollution threats to cultural heritage in a semi-confined environment: The case study of Michelozzo's Courtyard in Florence (Italy). Sci Total Environ 2010, 408(6):1403-1413. [http://www.sciencedirect.com/science/article/pii/ S0048969709006718]

19. Krupinska B, Worobiec A, Rotondo GG, Novakovic V, Kontozova V, Ro CU, Van Grieken R, De Wael K: Assessment of the air quality (NO2, SO2, 03 and particulate matter) in the Plantin-Moretus Museum/Print Room in Antwerp, Belgium, in different seasons of the year. Microchem J 2012, 102(0):49-53. [http://www.sciencedirect.com/science/article/pii/ S0026265X11002177]

20. Hanapi N, Din S: A Study on the airborne particulate matter in selected museums of peninsular Malaysia. Procedia - Soc Behav Sci 2012, 50(0):602-613. [http://www.sciencedirect.com/science/article/pii/ S1877042812032016]

21. Bonazza A, Messina P, Sabbioni C, Grossi CM, Brimblecombe P: Mapping the impact of climate change on surface recession of carbonate buildings in Europe. Sci Total Environ 2009, 407(6):2039-2050. [http:// www.ncbi.nlm.nih.gov/pubmed/19101018]

22. Yoon $\mathrm{YH}$, Brimblecombe $\mathrm{P}$ : The distribution of soiling by coarse particulate matter in the museum environment. Indoor air 2001, 11(4):232-240. [http://www.ncbi.nlm.nih.gov/pubmed/11761598]

23. Ferm M, Watt J, O'Hanlon S, De Santis F, Varotsos C: Deposition measurement of particulate matter in connection with corrosion studies. Anal Bioanal Chem 2006, 384(6):1320-1330. [http://www.ncbi. nlm.nih.gov/pubmed/16518649]

24. Andelova L, Smolik J, Ondrakova L, Ondracek J, Lopez-Aparicio S, Grontoft $T$, Stankiewicz J: Characterization of airborne particles in the Baroque Hall of the National Library in Prague. E-Preservation Sci 2010, 7:141-146. [http://www.morana-rtd.com/e-preservationscience/2010/ Andelova-26-04-2010.pdf]

25. Nazaroff WW: Airborne Particles in Museums. Marina del Rey Calif: Getty Conservation Institute; 1993. [http://www.getty.edu/conservation/ publications_resources/pdf_publications/pdf/airborne.pdf]

26. McMurry P, Shepherd M, Vickery J: Particulate Matter Science for Policy Makers: a NARSTO Assessment: EPRI Report 1007735,Cambridge: Cambridge University Press; 2004. [http://books.google.co.uk/books?id= $1 \mathrm{giH}-\mathrm{mvhhw8C]}$

27. AQEG: Particulate Matter in the UK. London: Defra; 2005.

28. Butterfield D, Beccaceci S, Quincey P, Sweeney B, Whiteside K, Fuller G, Green D, Grieve A: 2011 Annual report for the UK black carbon network. Tech. rep., National Physical Laboratory, Hampton Road, Teddington, Middlesex, TW11 OLW 2012 [http://uk-air.defra.gov.uk/ library/reports?report_id=730]

29. National air quality and emissions trends report. Tech. rep., United States Environmental Protection Agency, Office of Air Quality, Planning and Standards, Research Triangle Park NC 277112001

30. Querol X, Alastuey A, Rodriguez S, Plana F, Ruiz CR, Cots N, Puig O: PM10 and PM2.5 source apportionment in the Barcelona Metropolitan area, Catalonia, Spain. Atmos Environ 2001, 35(36):6407-6419. [http:// www.sciencedirect.com/science/article/pii/S1352231001003612]

31. Díaz-Robles $\mathrm{L}$, Fu J, Reed G: Modeling and source apportionment of diesel particulate matter. Environ Int 2008, 34:1-11. [http://www. sciencedirect.com/science/article/pii/S0160412007001109]

32. AQEG: Fine Particulate Matter (PM2.5) in the United Kingdom. London: Defra; 2012.

33. Yan F, Winijkul E, Jung S, Bond TC, Streets DG: Global emission projections of particulate matter (PM): I. Exhaust emissions from on-road vehicles. Atmos Environ 2011, 45(28):4830-4844. [http://www. sciencedirect.com/science/article/pii/S135223101100611X]

34. Streets DG, Gupta S, Waldhoff ST, Wang MQ, Bond TC, Yiyun B: Black carbon emissions in China. Atmos Environ 2001, 35(25): 4281-4296. [http://www.sciencedirect.com/science/article/pii/ S1352231001001790] 
35. Air quality guidelines for Europe. Tech. rep., World Health Organization Regional Office for Europe, WHO Regional Publications, Copenhagen 2000.

36. European Comission air quality standards. 2008. [http://ec.europa.eu/ environment/air/quality/standards.htm]

37. Buseck PR, Adachi K, Gelencsér A, Tompa E, Pósfai M: Are black carbon and soot the same? Atmos Chem Phys Discuss 2012, 12(9):24821-24846. [http://www.atmos-chem-phys-discuss.net/12/24821/2012/]

38. Song J, Wang J, Boehman AL: The role of fuel-born catalysts in diesel particulate oxidation behavior. Combustion Flame 2006, 146(12):73-84. [http://www.sciencedirect.com/science/article/pii/ S0010218006001143]

39. Lee KO, Cole R, Sekar R, Choi MY, Kang JS, Bae CS, Shin HD: Morphological investigation of the microstructure, dimensions, and fractal geometry of diesel particulates. Proc Combust Inst 2002, 29:647-653. [http://www.sciencedirect.com/science/article/pii/S1540748902800839]

40. Williams D, Milne J, Roberts D, Kimberlee M: Particulate emissions from in-use motor vehicles: Spark and ignition vehicles. Atmos Environ 1989, 23(12):2639-2645. [http://linkinghub.elsevier.com/retrieve/pii/ $0004698189905441]$

41. Mattimaricq $\mathrm{M}$ : Chemical characterization of particulate emissions from diesel engines: A review. J Aeroso/ Sci 2007, 38(11):1079-1118. [http://linkinghub.elsevier.com/retrieve/pii/S0021850207001231]

42. Sarvi A, Lyyränen J, Jokiniemi J, Zevenhoven R: Particulate emissions from large-scale medium-speed diesel engines: 2 . Chemical composition. Fuel Process Technol 2011, 92(10):2116-2122. [http:// linkinghub.elsevier.com/retrieve/pii/S0378382011002414]

43. Sahan $E$, Brink $H$, Weijers $E$ : Carbon in atmospheric particulate matter. Tech. rep., ECN Energy Research Centre of the Netherlands 2008.

44. Schauer JJ: Evaluation of elemental carbon as a marker for diesel particulate matter. J Exposure Anal Environ Epidemiol 2003, 13(6):443-453. [http://www.ncbi.nlm.nih.gov/pubmed/14603345]

45. Kendall M, Hamilton RS, Watt J, Williams ID: Characterisation of selected speciated organic compounds associated with particulate matter in London. Atmos Environ 2001, 35(14):2483-2495. [http://www. sciencedirect.com/science/article/pii/S1352231000004313]

46. Sotoa KF, Garzab KM, Shia Y, Murra LE: Direct contact cytotoxicity assays for filter-collected, carbonaceous (soot) nanoparticulate material and observations of lung cell response. Atmos Environ 2008, 42(9):1970-1982. [http://www.sciencedirect.com/science/article/pii/ S1352231007011296]

47. Pagels J, Wierzbicka A, Nilsson E, Isaxon C, Dahl A, Gudmundsson A, Swietlicki E, Bohgard M: Chemical composition and mass emission factors of candle smoke particles. J Aeroso/ Sci 2009, 40(3): 193-208. [http://www.sciencedirect.com/science/article/pii/ S0021850208001894]

48. Buonanno G, Morawska L, Stabile L: Particle emission factors during cooking activities. Atmos Environ 2009, 43(20):3235-3242. [http://www. sciencedirect.com/science/article/pii/S1352231009002775]

49. Jones N, Thornton C, Mark D, Harrison R: Indoor/outdoor relationships of particulate matter in domestic homes with roadside, urban and rural locations. Atmos Environ 2000, 34(16):2603-2612. [http:// linkinghub.elsevier.com/retrieve/pii/S1352231099004896]

50. Bernardi A, Camuffo D: Microclimate in the Chiericati Palace Municipal Museum, Vicenza. Mus Manage Curatorship 1995, 14:5-18. [http://www.sciencedirect.com/science/article/pii/026047799500020S]

51. Afshari A, Matson U, Ekberg LE: Characterization of indoor sources of fine and ultrafine particles: a study conducted in a full-scale chamber. Indoor Air 2005, 15(2):141-150. [http://dx.doi.org/10.1111/j. 1600-0668.2005.00332.x]

52. Na K, Cocker D: Organic and elemental carbon concentrations in fine particulate matter in residences, schoolrooms, and outdoor air in Mira Loma, California. Atmos Environ 2005, 39(18):3325-3333. [http:// linkinghub.elsevier.com/retrieve/pii/S1352231005001457]

53. Koponen IK, Asmi A, Keronen P, Puhto K, Kulmala M: Indoor air measurement campaign in Helsinki, Finland 1999 - the effect of outdoor air pollution on indoor air. Atmos Environ 2001, 35(8):1465-1477. [http://www.sciencedirect.com/science/article/pii/ S1352231000003381]

54. Hussein T, Hämeri K, Heikkinen MS, Kulmala M: Indoor and outdoor particle size characterization at a family house in Espoo-Finland.
Atmos Environ 2005, 39(20):3697-3709. [http://linkinghub.elsevier.com/ retrieve/pii/S1352231005002359]

55. Thornburg J, Ensor DS, Rodes CE, Lawless PA, Sparks LE, Mosley RB: Penetration of particles into buildings and associated physical factors. Part I: Model development and computer simulations. Aeroso/ Sci Technol 2001, 34(3):284-296. [http://www.tandfonline.com/ doi/abs/10.1080/02786820119886]

56. Gotschi T, Oglesby L, Mathys P, Monn C, Manalis N, Koistinen K, Jantunen M, Hanninen O, Polanska L, Kunzli N: Comparison of black smoke and PM2.5 levels in indoor and outdoor environments of four European cities. Environ Sci \& Technol 2002, 36(6):1191-1197. [http://www.ncbi.nlm nih.gov/pubmed/11944668]

57. Nazaroff WW: Indoor particle dynamics. Indoor Air 2004, 14(Suppl 7):175-183. [http://www.ncbi.nlm.nih.gov/pubmed/15330785]

58. Chao C: Penetration coefficient and deposition rate as a function of particle size in non-smoking naturally ventilated residences. Atmos Environ 2003, 37(30):4233-4241. [http://linkinghub.elsevier.com/retrieve/ pii/S1352231003005600]

59. Zhu Y, Hinds WC, Krudysz M, Kuhn T, Froines J, Sioutas C: Penetration of freeway ultrafine particles into indoor environments. J Aerosol Sci 2005, 36(3):303-322. [http://www.sciencedirect.com/science/article/pii/ S002185020400343X]

60. Ligocki MP, Salmon LG, Fall T, Jones MC, Nazaroff WW, Cass GR: Characteristics of airborne particles inside southern California museums. Atmos Environ 1993, 27(5):697-711. [http://www. sciencedirect.com/science/article/pii/0960168693901885]

61. Liu DL, Nazaroff WW: Particle penetration through building cracks. Aerosol Sci Technol 2010, 37(October 2011):37-41.

62. Liu DL, Nazaroff WW: Modeling pollutant penetration across building envelopes. Atmos Environ 2001, 35(26):4451-4462. [http://linkinghub. elsevier.com/retrieve/pii/S1352231001002187]

63. Tian L, Zhang G, Lin Y, Yu J, Zhou J, Zhang Q: Mathematical model of particle penetration through smooth/rough building envelop leakages. Building and Environ 2009, 44(6):1144-1149. [http://linkinghub. elsevier.com/retrieve/pii/S0360132308002047]

64. Hussein T, Glytsos T, Ondráček J, Dohányosová P, Ždímal V, Hämeri K, Lazaridis M, Smolík J, Kulmala M: Particle size characterization and emission rates during indoor activities in a house. Atmos Environ 2006, 40(23):4285-4307. [http://www.sciencedirect.com/science/article/ pii/S1352231006003554]

65. Viana M, Díez S, Reche C: Indoor and outdoor sources and infiltration processes of PM1 and black carbon in an urban environment. Atmos Environ 2011, 45(35):6359-6367. [http://www.sciencedirect.com/science/ article/pii/S1352231011008685]

66. Camuffo D, Sturaro G, Valentino A: Showcases: a really effective mean for protecting artworks? Thermochimica Acta 2000, 365(1-2):65-77. [http://www.sciencedirect.com/science/article/pii/S0040603100006146]

67. Weber S: Exposure of churchgoers to airborne particles. Environ SC Technol 2006, 40(17):5251-5256. [http://pubs.acs.org/doi/abs/10.1021/ es0517116]

68. Hirvonen A, Pasanen P, Tarhanen J, Ruuskanen J: Thermal desorption of organic compounds associated with settled household dust. Indoor Air 1994, 4(4):255-264. [http://dx.doi.org/10.1111/j.1600-0668.1994. 00006.x]

69. Pedersen EK, Bjorseth O, Syversen T, Mathiesen M: Physical changes of indoor dust caused by hot surface contact. Atmos Environ 2001, 35(24):4149-4157. [http://www.sciencedirect.com/science/article/pii/ S1352231001001959]

70. Mortensen LH, Rode C, Peuhkuri R: Investigation of airflow patterns in a microclimate by particle image velocimetry (PIV). Build Environ 2008, 43(11):1929-1938. [http://linkinghub.elsevier.com/retrieve/pii/ S0360132307002351]

71. Hinds WC: Aerosol Technology: Properties, Behavior, and Measurement of Airborne Particles. New York: Wiley; 1999. [http://books.google.co.uk books?id=ORxSAAAAMAAJ]

72. Camuffo D: Wall temperature and the soiling of murals. Mus Manage Curatorship 1991, 10(4):373-383. [http://www.sciencedirect.com/science/ article/pii/026047799190029W]

73. Nazaroff WW, Cass GR: Mathematical modeling of indoor aerosol dynamics. Environ Sci Technol 1989, 23(2):157-166. [http://pubs.acs.org/ doi/abs/10.1021/es00179a003] 
74. K Lai AC, Nazaroff WW: Modeling indoor particle deposition from turbulent flow onto smooth surfaces. J Aerosol Sci 2000, 31(4):463-476. [http://linkinghub.elsevier.com/retrieve/pii/S0021850299005364]

75. Nazaroff WW, Ligocki MP, M T, Cass GR: Particle deposition in museums: comparison of modeling and measurement results. Aerosol Sci Technol 1990, 13(3):332-348. [http://www.tandfonline.com/ doi/abs/10.1080/02786829008959449]

76. Hussein T, Hruška A, Dohányosová P, Džumbová L, Hemerka J, Kulmala M, Smolík J: Deposition rates on smooth surfaces and coagulation of aerosol particles inside a test chamber. Atmos Environ 2009, 43(4):905-914. [http://linkinghub.elsevier.com/retrieve/pii/ S1352231008010005]

77. Wallace $L$ : Effect of central fans and in-duct filters on deposition rates of ultrafine and fine particles in an occupied townhouse. Atmos Environ 2004, 38(3):405-413. [http://linkinghub.elsevier.com/retrieve/pii/ S1352231003008641]

78. He C, Morawska L, Gilbert D: Particle deposition rates in residential houses. Atmos Environ 2005, 39(21):3891-3899. [http://linkinghub. elsevier.com/retrieve/pii/S1352231005002815]

79. Zhao $B, \mathrm{Wu}$ J: Modeling particle deposition onto rough walls in ventilation duct. Atmos Environ 2006, 40(36):6918-6927. [http://www. sciencedirect.com/science/article/pii/S1352231006006698]

80. Thatcher TL, Lai AC, Moreno-Jackson R, Sextro RG, Nazaroff WW: Effects of room furnishings and air speed on particle deposition rates indoors. Atmos Environ 2002, 36(11):1811-1819. [http://linkinghub. elsevier.com/retrieve/pii/S1352231002001577

81. Guingo M, Minier JP: A new model for the simulation of particle resuspension by turbulent flows based on a stochastic description of wall roughness and adhesion forces. J Aerosol Sci 2008, 39(11):957-973. [http://linkinghub.elsevier.com/retrieve/pii/S0021850208001171]

82. Thatcher $T L$, Layton DW: Deposition, resuspension, and penetration of particles within a residence. Atmos Environ 1995, 29(13):1487-1497.

83. Ferro AR, Kopperud RJ, Hildemann LM: Source strengths for indoor human activities that resuspend particulate matter. Environ $\mathrm{SCi}$ Technol 2004, 38(6):1759-1764. [http://www.ncbi.nlm.nih.gov/pubmed/ 15074686]

84. Kontozova-Deutsch V, Cardell C, Urosevic M, Ruiz-Agudo E, Deutsch F, Van Grieken R: Characterization of indoor and outdoor atmospheric pollutants impacting architectural monuments: the case of San Jerónimo Monastery (Granada, Spain). Environ Earth Sci 2011, 63:1433-1445. [http://dx.doi.org/10.1007/s12665-010-0657-5]

85. Lazaridis M, Drossinos $Y$ : Multilayer resuspension of small identical particles by turbulent flow. Aerosol Sci Technol 1998, 28(June 2012):37-41. [http://www.tandfonline.com/doi/abs/10.1080/ 02786829808965545]

86. Lazaridis M, Drossinos Y, Georgopoulos P: Turbulent resuspension of small nondeformable particles. J Colloid Interface Sci 1998, 204:24-32. [http://www.ncbi.n/m.nih.gov/pubmed/9665763]

87. Biasi L, Reyes ADL, Reeks MW, Santi GFD: Use of a simple model for the interpretation of experimental data on particle resuspension in turbulent flows. J Aerosol Sci 2001, 32(10):1175-1200

88. Loosmore GA: Evaluation and development of models for resuspension of aerosols at short times after deposition. Atmos Environ 2003, 37(1352):639-647.

89. Schnell M, Cheung C, Leung C: Investigation on the coagulation and deposition of combustion particles in an enclosed chamber with and without stirring. J Aeroso/ Sci 2006, 37(11):1581-1595. [http:// linkinghub.elsevier.com/retrieve/pii/S0021850206000942]

90. Gidhagen L, Johansson C, Langner J, Foltescu V: Urban scale modeling of particle number concentration in Stockholm. Atmos Environ 2005, 39:1711-1725. [http://linkinghub.elsevier.com/retrieve/pii/ S1352231004011033]

91. Schnell M, Cheung C, Leung C: Coagulation of diesel particles in an enclosed chamber. J Aeroso/ Sci 2004, 35(10):1289-1293. [http:// linkinghub.elsevier.com/retrieve/pii/S0021850204000874]

92. Morawska $L$, Jamriska M, Bofinger ND: Size characteristics and ageing of the environmental tobacco smoke. Sci Total Environ 1997, 196:43-55. [http://linkinghub.elsevier.com/retrieve/pii/S0048969796053880]

93. Eastwood P: Particulate Emissions from Vehicles. Wiley-professional engineering publishing series, New York: John Wiley \& Sons; 2008. [http:// books.google.co.uk/books?id=ihLfwQJOHPEC]
94. Gidhagen L, Johansson C, Langner J, Olivares G: Simulation of NOx and ultrafine particles in a street canyon in Stockholm, Sweden. Atmos Environ 2004, 38(14):2029-2044. [http://linkinghub.elsevier.com/retrieve/ pii/S1352231004001372]

95. Jamriska M, Morawska L: Quantitative assessment of the effect of surface deposition andcoagulation on the dynamics of submicrometer particles indoors. Aeroso/ Sci Techno/ 2003, 37(5):425-436. [http://www.tandfonline.com/doi/abs/10.1080/ 02786820300975]

96. Gidhagen L, Johansson C, Strom J, Kristensson A, Swietlicki E, Pirjola L, Hansson HC: Model simulation of ultrafine particles inside a road tunnel. Atmos Environ 2003, 37(15):2023-2036. [http://www. sciencedirect.com/science/article/pii/S1352231003001249]

97. Ketzel M, Berkowicz R: Modelling the fate of ultrafine particles from exhaust pipe to rural background: an analysis of time scales for dilution, coagulation and deposition. Atmos Environ 2004, 38(17):2639-2652. [http://www.sciencedirect.com/science/article/pii/ S1352231004001724]

98. Hanley JT, Ensor DS, Smith DD, Sparks LE: Fractional aerosol filtration efficiency of in-duct ventilation air cleaners. Indoor Air 1994, 4:169-178.

99. ASHRAE: Museums, libraries and archives. In Heating, Ventilating and Air-Conditioning: Applications. ASHRAE Handbook. Atlanta: ASHRAE; 2003.

100. Brimblecombe $P$, Grossi CM: Aesthetic thresholds and blackening of stone buildings. Sci Total Environ 2005, 349(1-3):175-189. [http://wwW. ncbi.nlm.nih.gov/pubmed/16198679]

101. Hamilton $R$, Mansfield $T$ : The soiling of materials in the ambient atmosphere. Atmos Environ 1992, 26(18):3291-3296. [http://www. sciencedirect.com/science/article/pii/096016869290345L]

102. Bellan LM, Salmon LG, Cass GR: A Study on the human ability to detect soot deposition onto works of art. Environ Sci Technol 2000, 34(10):1946-1952. [http://pubs.acs.org/doi/abs/10.1021/es990769f]

103. Pio CA, Ramos MM, Duarte AC: Atmospheric aerosol and soiling of external surfaces in an urban environment. Atmos Environ 1998, 32(11):1979-1989. [http://linkinghub.elsevier.com/retrieve/pii/ S1352231097005074]

104. Adams S: A particle accumulation study during the reconstruction of The Great Court, British Museum. J Cult Heritage 2002, 3(4) 283-287. [http://linkinghub.elsevier.com/retrieve/pii/ S1296207402012372]

105. Mansfield T, Hamilton R, Ellis B, Newby P: Diesel particulate emissions and the implications for the soiling of buildings. Environmentalist 1991, 11(4):243-254. [http://www.springerlink.com/index/10.1007/ BF01266558]

106. Ford D: Deposition rates of particulate matter in the internal environment of two London museums. Atmos Environ 1999 33(29):4901-4907. [http://linkinghub.elsevier.com/retrieve/pii/ S1352231099002897]

107. Schwar MJR: Nuisance dust deposition and soiling rate measurements. Environ Technol 1998, 19(2):223-229. [http://www. tandfonline.com/doi/abs/10.1080/09593331908616674]

108. Beloin NJ, Haynie FH: Soiling of building materials. J Air Pollut Control Assoc 1975, 25(4):399-403. [http://www.tandfonline.com/doi/abs/10. 1080/00022470.1975.10470099]

109. Grossi C: Soiling of building stones in urban environments. Build Environ 2003, 38:147-159. [http://linkinghub.elsevier.com/retrieve/pii/ S0360132302000173]

110. Watt J, Tidblad J, Kucera V, Hamilton R: The Effects of Air Pollution on Cultural Heritage. New York: Springer; 2009. [http://books.google.co.uk/ books?id=AgHp6udMwOIC]

111. Brimblecombe $P$, Grossi CM: Millennium-long damage to building materials in London. Sci Total Environ 2009, 407(4):1354-1361. [http:// www.ncbi.nlm.nih.gov/pubmed/19036411]

112. Pesava P, Aksu R, Toprak S, Horvath H, Seidl S: Dry deposition of particles to building surfaces and soiling. Sci Total Environ 1999 235(1-3):25-35. [http://linkinghub.elsevier.com/retrieve/pii/ S0048969799001874]

113. Ionescu A, Lefèvre RA, Chabas A, Lombardo T, Ausset P, Candau Y, Rosseman $L$ : Modeling of soiling based on silica-soda-lime glass exposure at six European sites. Sci Total Environ 2006 369(1-3):246-255. [http://www.ncbi.nlm.nih.gov/pubmed/16777189] 
114. Lombardo T, lonescu A, Chabas A, Lefèvre RA, Ausset P, Candau Y: Dose-response function for the soiling of silica-soda-lime glass due to dry deposition. Sci Total Environ 2010, 408(4):976-984. [http://www. ncbi.nlm.nih.gov/pubmed/19900698]

115. Lombardo T, lonescu A, Lefèvre RA, Chabas A, Ausset $\mathrm{P}$, Cachier $\mathrm{H}$ : Soiling of silica-soda-lime float glass in urban environment: measurements and modelling. Atmos Environ 2005, 39(6): 989-997. [http://www.sciencedirect.com/science/article/pii/ S1352231004010088]

116. Tidblad J, Kucera V, Schreiner M, Melcher M, Kreislova K, Watt J, Hamilton R: Multi Assess report (Model for multi-pollutant impact andd assessment of threshold levels for cultural heritage). Tech. rep., Swedish Corrosion Institute (SCI), Stockholm, Sweden 2005, [www.corr-institute.se/MULTI-ASSESS]

117. Timmer $\mathrm{H}$, Zeller M: Particle deposition near ceiling induction outlets. Int J Refrigeration 2004, 27(3):248-254. [http://www. sciencedirect.com/science/article/pii/S014070070300166X]

118. Camuffo D, Pagan E, Bernardi A, Becherini F: The impact of heating, lighting and people in re-using historical buildings: a case study. $\lrcorner$ Cultural Heritage 2004, 5(4):409-416. [http://www.sciencedirect.com/ science/article/pii/S1296207404000822]

119. Zhang H, Shi M, Shen W, Li Z, Zhang B, Liu R, Zhang R: Damage or protection? The role of smoked crust on sandstones from Yungang Grottoes. J Archaeological Sci 2013, 40(2):935-942. [http://www. sciencedirect.com/science/article/pii/S0305440312004335]

120. Vigil F: Black stains in houses: soot, dust, or ghosts? Home Energy Mag Online 1988. [http://www.homeenergy.org/show/article/id/1360]

121. Morawska L, Salthammer T: Indoor Environment. New York: Wiley; 2006. [http://books.google.co.uk/books?id=ogTHwrb6e60C]

122. Salthammer T, Uhde E: Organic Indoor Air Pollutants. New York: Wiley; 2009. [http://books.google.co.uk/books?id=bo7icxgj-DkC]

123. Fittschen UEA, Santen M, Rehmers A, Durukan I, Wesselmann M: Indoor aerosol determination with respect to a soiling phenomenon in private residences. Environ Sci Technol 2013, 47:608-615. [http://pubs. acs.org/doi/abs/10.1021/es303281k]

124. Salthammer T, Fauck C, Schripp T, Meinlschmidt P, Willenborg S, Moriske $\mathrm{HJ}$ : Effect of particle concentration and semi-volatile organic compounds on the phenomenon of "black magic dust" in dwellings. Build Environ 2011, 46(10):1880-1890. [http://www.sciencedirect.com/ science/article/pii/S0360132311000795]

125. Zai S, Zhen H, Jia-song W: Studies on the size distribution, number and mass emission factors of candle particles characterized by modes of burning. J Aeroso/ Sci 2006, 37(11):1484-1496. [http://www. sciencedirect.com/science/article/pii/S0021850206000899]

126. Bond TC, Bergstrom RW: Light absorption by carbonaceous articles: an investigative review. Aeroso/ Sci Technol 2006, 40:27-67. [http:// www.tandfonline.com/doi/abs/10.1080/02786820500421521]

127. Zhang Q, Rubini P: Modelling of light extinction by soot particles. Fire Safety J 2011, 46(3):96-103. [http://www.sciencedirect.com/science/ article/pii/S0379711210000913]

128. Grossi CM, Brimblecombe P, Esbert RM, Alonso FJ: Color changes in architectural limestones from pollution and cleaning. Color Res \& App/ 2007, 32(4):320-331. [http://doi.wiley.com/10.1002/col.20322]

129. Grossi CM, Brimblecombe $P$ : Aesthetics of simulated soiling patterns on architecture. Environ Sci Technol 2004, 38(14):3971-3976. [http:// www.ncbi.nlm.nih.gov/pubmed/15298208]

130. Tétreault J: Airborne Pollutants in Museums, Galleries and Archives: Risk Assessment, Control Strategies and Preservation Management. Ottawa: Canadian Conservation Institute; 2003. [http://books.google.co.uk/books? $\mathrm{id}=\mathrm{zB} 18 \mathrm{QgAACAAJ}$

131. Druzik JR, Cass GR: A new look at soiling of contemporary paintings by soot in art museums. In The Indoor Air Quality Meeting for Museums Conference Report. Oxford: Oxford Brookes University; 2000:22-27.

132. Rodriguez-Navarro C, Sebastian E: Role of particulate matter from vehicle exhaust on porous building stones (limestone) sulfation. Sci Total Environ 1996, 187(2):79-91. [http://linkinghub.elsevier.com/retrieve/ pii/0048969796051248]

133. Simão J, Ruiz-Agudo E, Rodriguez-Navarro C: Effects of particulate matter from gasoline and diesel vehicle exhaust emissions on silicate stones sulfation. Atmos Environ 2006, 40(36):6905-6917. [http:// linkinghub.elsevier.com/retrieve/pii/S1352231006006704]
134. Strandberg H: Reactions of copper patina compounds-I. Influence of some air pollutants. Atmos Environ 1998, 32(20):3511-3520. [http:// www.sciencedirect.com/science/article/pii/S1352231098000570]

135. Jacobson M: Atmospheric Pollution: History, Science, and Regulation. Cambridge: Cambridge University Press; 2002. [http://books.google.co. uk/books?id=NN5S0_3dEvkC]

136. Popovicheva OB, Persiantseva NM, Kireeva ED, Khokhlova TD, Shonija NK: Quantification of the hygroscopic effect of soot aging in the atmosphere: laboratory simulations. J Phys Chem A 2011 115(3):298-306. [http://pubs.acs.org/doi/abs/10.1021/jp109238x]

137. Perez-Alonso M, Castro K, Martinez-Arkarazo I, Angulo M, Olazabal MA, Madariaga JM, Pérez-Alonso M: Analysis of bulk and inorganic degradation products of stones, mortars and wall paintings by portable Raman microprobe spectroscopy. Anal Bioanalytical Chem 2004, 379:42-50. [http://link.springer.com/article/10.1007\%2Fs00216004-2496-2], http://www.ncbi.nlm.nih.gov/pubmed/14758463.

138. Duran A, Perez-Rodriguez J, de Haro MJ, Herrera L, Justo A: Degradation of gold and false golds used as gildings in the cultural heritage of Andalusia, Spain. J Cult Heritage 2008, 9(2):184-188. [http://www. sciencedirect.com/science/article/pii/S1296207408000253]

139. Askey A, Lyon S, Thompson G, Johnson J: The effect of fly-ash particulates on the atmospheric corrosion of zinc and mild steel. Corrosion Sci 1993, 34(7):1055-1081. [http://www.sciencedirect.com/ science/article/pii/0010938X9390289S]

140. Montanaro L: Durability of ceramic filters in the presence of some diesel soot oxidation additives. Ceramics Int 1999, 25:437-445. [http:// www.sciencedirect.com/science/article/pii/S0272884298000510]

141. Brimblecombe $P$, Thickett $D$, Yoon $\mathrm{YH}$ : The cementation of coarse dust to indoor surfaces. J Cult Heritage 2009, 10(3):410-414. [http:// linkinghub.elsevier.com/retrieve/pii/S1296207409000557]

142. The National Trust Manual of Housekeeping: the Care of Collections in Historic Houses Open to the Public: Henry Ford Estate collection, National Trust, Amsterdam: Elsevier; 2006. [http://books.google.co.uk/books?id= JKFVwVIZbWMC]

143. Spafford-Ricci S, Graham F: The fire at the Royal Saskatchewan Museum, Part 2: removal of soot from artifacts and recovery of the building. J Am Inst Conserv 2000, 39:37-56. [http://www.jstor.org/stable/ 3179962]

144. Strlič M, Kolar J, Šelih VS, Marinček M: Surface modification during Nd:YAG (1064 nm) pulsed laser cleaning of organic fibrous materials. App/ Surface Sci 2003, 207(1-4):236-245. [http://www. sciencedirect.com/science/article/pii/S0169433202013715]

145. Strlič M, Šelih VS, Kolar J, Kočar D, Pihlar B, Ostrowski R, Marczak J, Strzelec M, Marinček M, Vuorinen T, Johansson LS: Optimisation and on-line acoustic monitoring of laser cleaning of soiled paper. App/ Phys A: Mater Sci Process 2005, 81(5):943-951. [http://dx.doi.org/10.1007/ s00339-005-3268-3]

146. Toniolo L, Zerbi C, Bugini R: Black layers on historical architecture. Environ Sci Pollut Res 2009, 16:218-226. [http://dx.doi.org/10.1007/ s11356-008-0046-8

doi:10.1186/2050-7445-1-8

Cite this article as: Grau-Bové and Strlič: Fine particulate matter in indoor cultural heritage: a literature review. Heritage Science 2013 1:8. 